\title{
CARDIAC CATHETERIZATION IN THE DIAGNOSIS OF CONGENITAL HEART DISEASE*
}

\author{
BY \\ H. E. HOLLING AND G. A. ZAK * \\ From the Clinical Research Unit and the Cardiac Department, Guy's Hospital \\ Received October 24, 1949
}

Cardiac catheterization is now a recognized method of clinical investigation and in recent years has been applied to the diagnosis of malformed hearts (Cournand et al., 1949; Warren et al., 1946; Groom et al., 1948; Handelsman et al., 1948; Dexter et al., 1947; Bing et al., 1947; Taylor et al., 1948; Burchell et al., 1948; Geiger et al., 1946; Brannon et al., 1945; Howarth et al., 1947; Baldwin et al., 1946; Soulie et al., 1949). So far we have used this method on a group of 70 patients with a wide range of cardiac malformations. Here we attempt to evaluate the method as a diagnostic procedure, using the published results of other workers to supplement our own experience.

\section{CASES InVestigated}

The cases were selected from a large number sent to Guy's Hospital mainly with a view to surgical treatment of their condition; they were under the care of Dr. Maurice Campbell, Mr. R. C. Brock, and Dr. Charles Baker, and clinical diagnoses were often discussed together. Patients with congenital heart disease often have multiple cardiac malformations of which one may be judged as functionally the most important, and in the table below they are listed under what appears to be the chief lesion. Thirty-six were over 15 years of age, twenty-two between the ages of 10 and 15 , and twelve between the ages of 5 and 10 years.

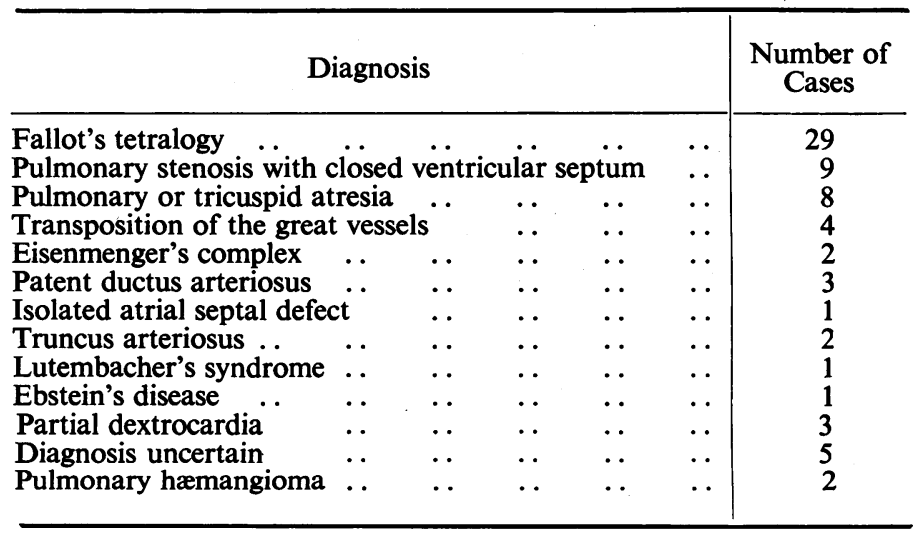

At the end of the paper the results of catheterization of 18 illustrative cases are given, with explanatory notes intended to show how the general principles of interpreting results apply in particular cases. The diagnosis of some of these cases, in spite of angiocardiography and cardiac

* Work undertaken on behalf of the Medical Research Council. G. A. Z. was in receipt of a personal grant from the Medical Research Council. 
catheterization, is still in doubt, but they have been included to represent problems that arise in practice. Several of the cases have been or will be discussed elsewhere (Allanby and Campbell, 1949; Baker et al., 1949; Brock, 1948; Campbell and Hills, 1950). We have not attempted to catheterize all the cases admitted, because we find the procedure too time-consuming to be used in this way. It requires a full day's work for two investigators and a technician, and the co-operation of the X-ray staff for at least two hours. Moreover, the investigation is not without danger to the patient, who in any case is likely to find it an uncomfortable experience. We have therefore restricted its use mainly to those where the clinical diagnosis was in doubt, or where it seemed important to obtain the information that cardiac catheterization can yield.

\section{MethodS}

The methods used do not differ materially from those of other workers and we comment only on points that seem important.

Sedation and ancesthesia. It is known (Hickam et al., 1948) that anxiety on the part of the patient may increase the cardiac output without a parallel increase in oxygen consumption, thus decreasing the arteriovenous oxygen difference. Moreover, breath holding, crying, or struggling may materially alter the intracardiac pressures and gaseous content of the blood. It is important, therefore, that so far as possible the patient should remain under basal conditions throughout the catheterization. It is not easy to achieve this, particularly with children, because the method requires that the patient lie on the X-ray table for at least an hour. Moreover, the passage of the catheter into the heart often provokes tachycardia and sometimes extrasystoles, and in some patients manipulation of the catheter in the right ventricle causes a complaint of soreness under the sternum. We found that to engage the patient in easy conversation throughout the procedures is the best way of ensuring equable conditions. It is certainly undesirable to discuss technical points in the hearing of the patient. One to three grains of phenobarbitone were given about two hours before the start to adults and children down to the age of 8 years. Younger children, with one exception, required an anæsthetic. For this we first tried trilene or paraldehyde, which were recommended by the anæsthetists as being the safest agents, but their use disturbed the subsequent blood gas determinations. We have since found avertin satisfactory, given per rectum in a dose of $0.125 \mathrm{~g}$. per $\mathrm{kg}$. about half an hour before the insertion of the catheter. When deeper unconsciousness was required, avertin was supplemented with pentothal (about $0.15 \mathrm{~g}$.). Though deepening of the anæsthesia probably altered the condition of the patient, it seemed preferable to risk this rather than to withdraw blood samples from a crying or struggling child.

Catheterization. The Cournand catheter was introduced into a cubital vein draining into the basilic system. The catheter sizes used ranged from 7 to 10 , but usually an 8 or 9 was employed. A number of difficulties were met with during catheterization. It is inadvisable to try to force a catheter into a vein too small to accommodate it comfortably. In one instance when we attempted this an extensive thrombosis of the vein followed. On occasion the vein appeared to contract strongly, gripping the catheter and making its passage difficult. Usually in the experience of others and ourselves this can be avoided by gentle and smooth manipulation of the catheter. This happened once when the catheter tip was at the level of the outer border of the first rib, and for an hour and a half the catheter could neither be advanced nor withdrawn. Then following the injection of $1.5 \mathrm{ml}$. of 1 per cent procaine, through and alongside the catheter, and the application of hot water bottles to the arm, the catheter became free.

Either arm has been used for the insertion of the catheter, but in cases with a right-sided aortic arch it has seemed easier to enter the superior vena cava from the left, probably because of the more favourable angle between the left innominate vein and the superior vena cava. In one such case the catheter could not be advanced into the superior vena cava from the right in spite of a prolonged trial, but from the left arm this was achieved without difficulty.

On several occasions during the exploration of the right atrium for suspected septal defects 
the tip of the catheter re-entered the superior vena cava and so formed a loop in the atrium. This has given rise to anxiety on the part of the operator because pushing the catheter caused the tip to move further into the vena cava, and pulling it caused the tip of the catheter to become wedged in the opening of the superior vena cava. On each occasion gentle manipulation of the catheter released it within a minute or two.

Since in our experience embolism has followed catheterization (see later) we emphasize the need for strict precautions against the formation of thrombi within the catheter or damage to the endocardium. The heparin saline drip ( 3000 units heparin per litre of normal saline) should be checked frequently, especially when entering chambers in which the blood is under high pressure, when it may be necessary to raise the saline reservoir. Manipulation of the catheter when inside the heart and great vessels, especially in the left ventricle, should be gentle to minimize the risk of trauma to the endothelium with subsequent thrombus formation. Cleaning the catheter should begin immediately after it is withdrawn.

Location of the catheter tip. In dealing with abnormal hearts in which unusual communications or obstructions may exist between the various chambers, it is important to locate the tip of the catheter as precisely as possible. The value of the lateral position should be remembered.

Fluoroscopic observation should start from the moment the catheter enters the thorax. The $\mathrm{X}$-ray screening time has, however, to be limited, and in accordance with the measurements of Hills and Stanford (1950) we endeavoured not to exceed 25 per cent of the erythema dose. For us this meant about 20 minutes' screening time, though the diaphragms of the apparatus were adjusted to give as small a field as was required for directing the catheter tip within the heart. It is permissible to extend the screening time by 25 per cent when necessary for the completion of an important case.

Frequent measurement of intracardiac pressure is a great help in locating the tip of the catheter. For this purpose we have used saline, aneroid, and Hamilton manometers (Hamilton, 1934). The saline manometer is unsatisfactory mainly because of the slowness with which it reaches equilibrium, particularly when blood has passed into the catheter. The aneroid manometer requires the movement of only a small volume of fluid through the system before equilibrium is reached and so records quickly, but like the saline manometer it does not record systolic and diastolic pressures. However, the mean pressure is usually sufficient for diagnostic purposes, and because the aneroid manometer is so simple to use it can be generally recommended. Since it is not unlikely that evidence of value for diagnosis may be derived from a study of the form of the intracardiac pulse tracings, we have also used a Hamilton manometer with optical recording.

To aid in locating the catheter tip it is an advantage to ascertain the oxygen content of the blood samples while the catheterization is in progress. With this object some workers have arranged to have the blood analysed as it is taken so that the results may be known before the catheter is withdrawn, and further samples taken if necessary. We have not been able to do this, but undoubtedly it would be of great value. Wood et al. (1948) have described a photoelectric apparatus that may prove useful. Using this, the oxygen saturation of blood withdrawn from the catheter can be estimated almost as soon as it is taken, and samples from different parts of a cardiac chamber or chambers can be compared; and if they vary considerably, as many samples as necessary can be taken to estimate the average oxygen saturation of blood in the particular chamber.

The catheter sometimes enters the coronary sinus from the right atrium, but with experience this is quickly recognized and corrected; the following points are important. (1) As the catheter passes along the narrow coronary sinus it follows a fixed path and the curved tip cannot be turned around as when lying in the ventricle. (2) The catheter may appear as if its tip is about to pass into the pulmonary artery and occasionally as if it had entered the left branch of the pulmonary artery, but it always comes to a full stop within the cardiac shadow. (3) Although the catheter tip looks as if it is in the ventricle the pressure recorded is as low as in the atrium. However, if the catheter is advanced until it blocks the cardiac vein the pressure rises towards ventricular pressure $(60 / 16 \mathrm{~mm}$. Hg in Case 13, Fig. 12). Bing (1949) gives a record of the fall in pressure as the catheter 
is withdrawn from blocking the cardiac vein. (4) The blood samples withdrawn from the coronary sinus are of a very low oxygen content ( 20 to $30 \%$ saturated).

Estimation of blood oxygen content. Blood samples from the catheter were withdrawn into vaselined syringes, and kept in them in the dark and in ice water until their oxygen content could be determined in a Haldane blood gas apparatus (Douglas and Priestley, 1948).

We found, as did Wassermann et al. (1949) and other investigators, that the oxygen content of the blood sometimes decreases if the blood is allowed to stand at room temperature. Our observations suggest this is not constant, for the blood sometimes shows only a negligible fall after standing at room temperature for 4 to 5 hours. In other cases, however, the blood oxygen content may show a considerable drop within an hour. In our experience the addition of sodium fluoride ( $0.6 \mathrm{mg}$./ml. blood) does not prevent the loss of oxygen. It is, however, greatly slowed by keeping the blood syringe in iced water, and kept in this way there is no material loss of oxygen over a period of 6 hours. For example, arterial blood was taken and the oxygen content (measured within 10 minutes of withdrawal) was found to be $15.4 \mathrm{ml} . / 100 \mathrm{ml}$. ( $81 \%$ saturation) : one-half of the sample was kept in iced water, the other at room temperature $\left(21^{\circ} \mathrm{C}\right.$.), and in all 13 estimations of oxygen content were done in the next 6 hours; these showed that the oxygen content of the blood kept in iced water remained steady for 6 hours at 15.4 to $15.3 \mathrm{ml}$. oxygen per $100 \mathrm{ml}$. but the oxygen content of that kept at room temperature slowly fell over $5 \frac{1}{2}$ hours to $14.6 \mathrm{ml}$. oxygen per $100 \mathrm{ml}$.

The blood was kept in the dark in order to prevent the formation of methæmoglobin, which is liable to form when blood is exposed to light.

\section{COMPLiCATIONS OF CATHETERIZATION}

Cardiac arrhythmias. Tachycardia up to 140 a minute in children may occur during catheterization, and is best avoided by the methods described under sedation. When the catheter tip is in the right ventricle the patient may be disturbed by extrasystoles but we have seen no harm come from them and our practice is to forewarn the patient and to reassure him that they are not of importance. Johnson et al. (1947) describe the onset of a paroxysm of auricular tachycardia or of 1 to 1 flutter which lasted for two hours after passing of a loop of catheter through the tricuspid orifice. Dexter et al. (1947) report auricular fibrillation in two of their patients with spontaneous restoration of normal rhythm within half an hour. Ventricular fibrillation is presumably a possibility though it has not been recorded.

General reactions. During the insertion of the catheter two of our female patients fainted, showing a cold, pale, sweating skin and a slow pulse; this occurred though they were supine and not complaining of any pain or discomfort. Several patients, especially when the catheterization has been prolonged, have complained of nausea immediately after the withdrawal of the catheter, and for the next five or six hours have felt very tired. Three children vomited immediately after and became temporarily more cyanosed; they also were extremely fatigued. Since any increase in the degree of the anoxia of these patients is dangerous, we have always had means of administering oxygen at hand.

Thrombosis and embolism. Localized thrombosis of the vein where the catheter was inserted often occurs, but it seldom extends far up the vein. Cournand (1949) finds that thrombosis is more likely to be limited if the incision is made at least $5 \mathrm{~cm}$. distal to the opening of a branch vein into the basilic system.

It is generally held that cardiac catheterization is a safe procedure in man, and so far as we are aware there is only one reported case in which it is possible that catheterization had given rise to fatal thrombosis and embolism (Johnson et al., 1947). The child died of an unspecified cause one month after catheterization and an unsuspected thrombus was found in the right atrium, inferior vena cava, and iliac and renal veins. Presumably the thrombosis had arisen at the site of the insertion of the catheter into the saphenous vein, or perhaps at the base of one of the tricuspid valves to which it was attached. Kinney et al. (1945) subjected the hearts of dogs to " traumatic" 
catheterization for short periods and subsequent pathological examination of the hearts and great vessels showed no lesions attributable to the procedure. On the other hand some members of the same group later reported verbally endocardial lesions in dogs after catheterization of the pulmonary artery (Goodale et al., 1947). Goodale had found mural thrombi and subendocardial hæmorrhages in the hearts of dogs that had been catheterized. These lesions were found to be more distinct when the animals were sacrificed more than 24 hours after the catheterization, and perhaps this may be the reason for the conflicting descriptions. In our experience with cases of congenital heart disease, cardiac catheterization is not without danger to the patient. Symptoms and signs indicating pulmonary or systemic thromboses or emboli have developed within 14 days of catheterization in no less than 6 of the 70 cases here reported. Details of these cases are as follows:

(1) O. D., aged 23 years (Case 9 of the appendix), a case of Eisenmenger's complex developed (the day after catheterization) an extensive thrombosis of her brachial vein. Seven days later she complained of pain in her chest and coughed up blood-stained sputum.

(2) C. L., aged 7 years (Case 13 of the appendix), had an unusual malformation of the heart described there. She was deeply cyanosed and bedridden, and was the most severley incapacitated of the children we have examined. Immediately after the withdrawal of the catheter she vomited and rapidly became unconscious and stopped breathing. Artificial respiration and oxygen were given for several minutes before consciousness returned. The next day she coughed up bloody sputum and remained critically ill for a fortnight. Having apparently recovered from the catheterization and a subsequent angiocardiogram, she died suddenly about seven weeks after the catheterization. No evidence of presumed pulmonary infarcts or of intravascular thrombi was found at necropsy.

(3) and (4) J. C. and R. C., aged 8 years, Fallot's tetralogy and tricuspid atresia respectively. Both complained of pain in the chest a few hours after catheterization, became dyspnœic and more cyanosed. J. C. had blood-stained sputum. They were nursed in an oxygen tent for a few days till they recovered.

(5) B. H., aged 10 years, a case of transposition of the great vessels. During catheterization the aorta was entered a number of times. About 8 hours after the catheterization he developed pyrexia, headache, and increasing drowsiness. The next day he was semiconscious, had neck rigidity, and a positive Kernig's sign. Lumbar puncture showed the cerebrospinal fluid to be under pressure and to contain blood. Several days later he also had diarrhœa. Chemotherapy was given from the start of his symptoms, but it was 3 weeks before he was well again. This unexpected sequel was thought to be the result of intravascular thrombosis.

(6) L. H., aged 19. Case described in detail (Baker et al., 1950). One week after catheterization he developed sudden pain in both calves and died with bilateral gangrene of the legs 10 days later. At necropsy he was found to have the abnormality of the tricuspid valves known as Ebstein's disease. A partly organized thrombus was found on the septal wall of the left ventricle, which the catheter had entered via an atrial septal defect. In both popliteal arteries emboli were found, which had presumably originated from the intracardiac thrombosis.

Even without catheterization, thromboses and emboli may occur in these patients and at necropsy vegetations are often found on the deformed valves and edges of septal defects. In view of this tendency to spontaneous thromboses it is perhaps not unexpected that it should sometimes follow cardiac catheterization. To reduce the likelihood of endothelial damage we prefer to use the thinner and more flexible catheters, even though they are more difficult to direct in the heart.

\section{The INTERPRetation of The Results of BloOd Gas Estimations}

The clinical differentiation of congenital heart disease may be uncertain because of the frequent occurrence of multiple defects. It is in this field that cardiac catheterization is being applied extensively, for by its use the presence of certain malformations may be proved. If, for instance, the catheter passes through a septal defect the fact can be recognized on the X-ray screen, or if the catheter is passed in to the pulmonary artery the stenosis can be recognized by the fall in pressure as the catheter tip passes through it. Often, however, direct proof is not obtained, though evidence of the defect may be found indirectly from comparison of the oxygen content of blood from the great vessels and chambers of the right heart.

An atrial septal defect with an arteriovenous shunt will result in blood in the right atrium being more oxygenated than blood in the venæ cavæ, or a patent ductus arteriosus will result in the blood 
in the pulmonary artery being more oxygenated than in the right ventricle. Blood may flow either into the right or the left heart, and while an arteriovenous shunt would cause an increase in the oxygen content of the right heart blood, a venoarterial shunt would have no such effect. In practice it is not always easy to say whether an increase in oxygen content of the blood from right atrium, ventricle, or pulmonary artery indicates an admixture of oxygenated blood through a septal defect. This is because there are considerable variations in oxygen content of right heart blood, even in hearts with no septal defects or other abnormal communications. It is, therefore, important to know these variations so that the diagnosis of a septal defect may be made with more confidence.

\section{Comparison of Blood from the Venæ Cave and Atrium}

The difference in oxygen content that may occur between the blood of the venæ cavæ and the right atrium in the absence or presence of atrial septal defects is shown by the data from our own cases and those of other workers in Fig. 1, 2, and 3. The cases without atrial septal defect include not only malformed hearts, but also acquired heart disease and normal hearts. The diagnosis of an atrial septal defect, and whether the shunt through it was venoarterial or arteriovenous, was made on good clinical evidence, and in some cases confirmed by examination of the heart after

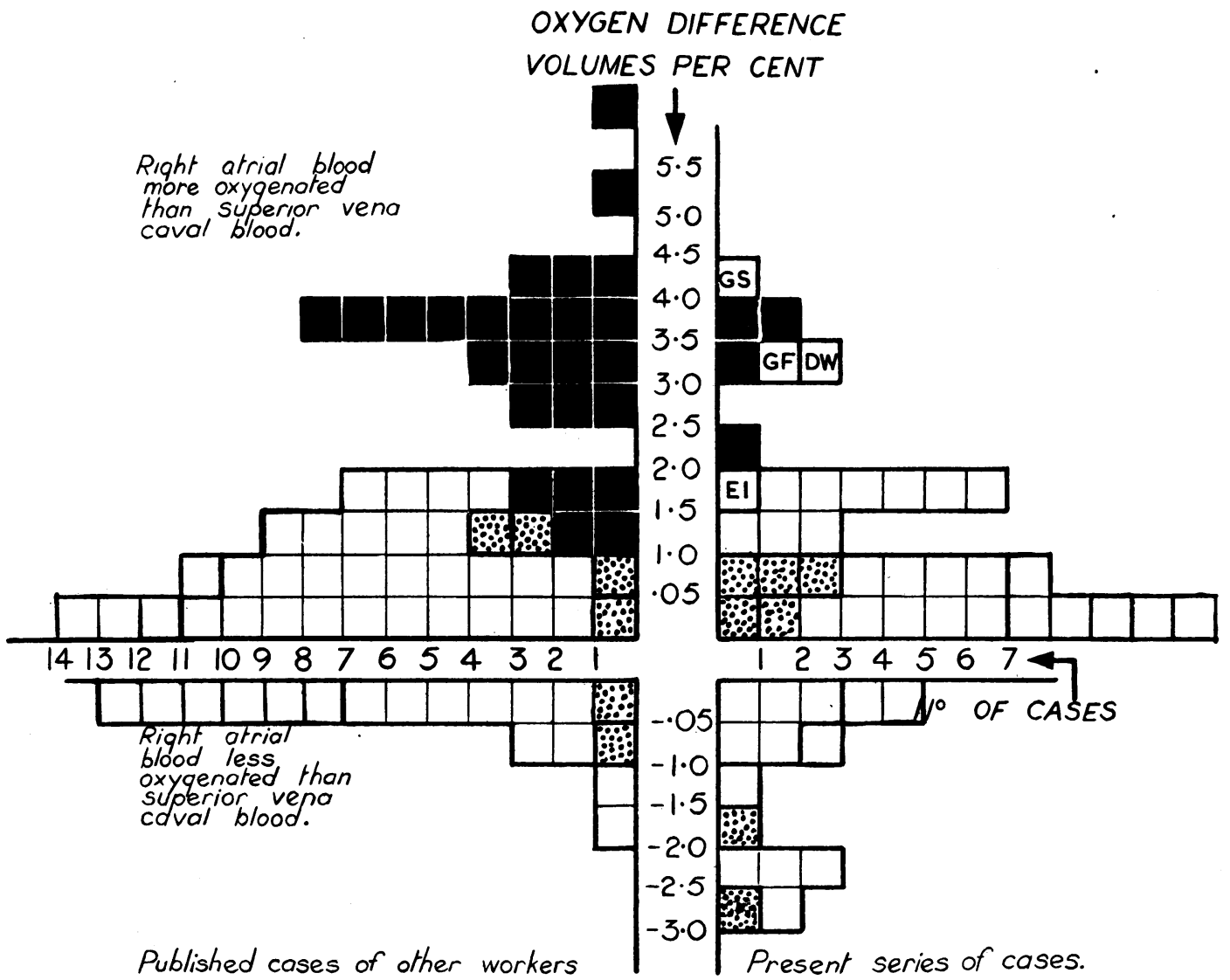

FIG. 1.-Differences in oxygen content (volumes per cent) of superior vena caval and right atrial bloods in 131 patients. The white squares represent cases with no atrial septal defect, black squares with an atrial septal defect through which a predominantly arteriovenous shunt occurs, and stippled squares with an atrial septal defect through which a predominantly venoarterial shunt occurs. The significance of the initialled squares is given in the text. 
death. Cases in which the diagnosis of atrial septal defect was made largely or solely on the comparison of the oxygen content of blood samples could not, of course, be included in this series.

In Fig. 1, 2, and 3, the cases without atrial septal defect are shown as white squares, those with an atrial septal defect and a predominantly venoarterial shunt as stippled squares, and those with a predominantly arteriovenous shunt as black squares. The four lettered squares refer to cases that are discussed below.

\section{Superior Vena Caval and Right Atrial Blood (Fig. 1)}

Fig. 1 shows that in two-thirds of 95 patients with no atrial septal defect the oxygen content of right atrial blood exceeds that of superior vena caval blood, and that the difference may be as much as 2.0 volumes per cent. Of the other one-third with oxygen content of blood in the atrium lower than that in the superior vena cava, the majority show a difference of no more than 1 volume per cent, though this may reach as much as 3 volumes per cent. It follows that the diagnosis of an atrial septal defect with an arteriovenous shunt can only be made on the comparison of the oxygen content of blood samples if that from the right atrium exceeds that from the superior vena cava by more than 2 volumes per cent.

Using the standard of 2 volumes per cent a septal defect with arteriovenous shunt will be recognized in the large majority of cases; but a few, in which the difference lies between 1 and 2 volumes per cent, will be missed.

In those cases of atrial septal defect with a venoarterial shunt, the difference of oxygen content between superior vena caval blood and right atrial blood lies as would be expected, within the range of those with no atrial septal defect.

\section{Inferior Vena Caval and Right Atrial Blood (Fig. 2)}

Most workers have compared only superior vena caval and right atrial blood. Dexter et al. (1947), however, took blood samples from a few centimetres below the diaphragm and found that such blood from the inferior vena cava had a uniformly higher oxygen content than that from the superior vena cava or atrium. They believed that this was largely due to the influence of renal vein blood and abandoned the use of blood from the inferior vena cava for comparative purposes, relying solely on the comparison of right atrial and superior vena caval bloods. We have taken inferior vena caval samples routinely from a point just below the diaphram and find that the oxygen content is often, though not always, higher than that of atrial blood. Thus Fig. 2 shows that of 55 cases with intact atrial septa, in 34 the inferior vena caval blood was more oxygenated than that of the atrium, usually the difference was within 1 volume per cent, but reached as much as 3 volumes per cent. On the other hand, in 21 cases the inferior vena caval blood was less oxygenated than atrial blood; in most cases the difference was no more than 1 volume per cent, but exceptionally it was as great as 3 volumes per cent.

It is clear that if inferior vena caval blood is used for comparative purposes a higher oxygen difference (as much as 3 volumes per cent) must exist before a diagnosis of atrial septal defect can be made, and also that in a greater proportion of cases the diagnosis would be missed than when using superior vena caval blood.

It will be noted that in cases with a venoarterial shunt through the atrial septal defect the oxygen difference of inferior vena caval blood and atrial blood lies within the normal range.

Consideration of the oxygen content of inferior caval blood further demonstrates that (1) the vessel may contribute a stream of relatively oxygenated blood to the right atrium, (2) that for comparative purposes it would be better to use samples of both superior and inferior caval bloods, and to compare the mean of these two with that of the atrium.

\section{Comparison of Right Atrial and Mean of Superior and Inferior Vena Caval Blood Samples (Fig. 3)}

The difference in oxygen content of right atrial blood and the mean of inferior and superior vena caval blood (caval blood) in 84 patients is seen in Fig. 3. In 29 cases the right atrial blood was 


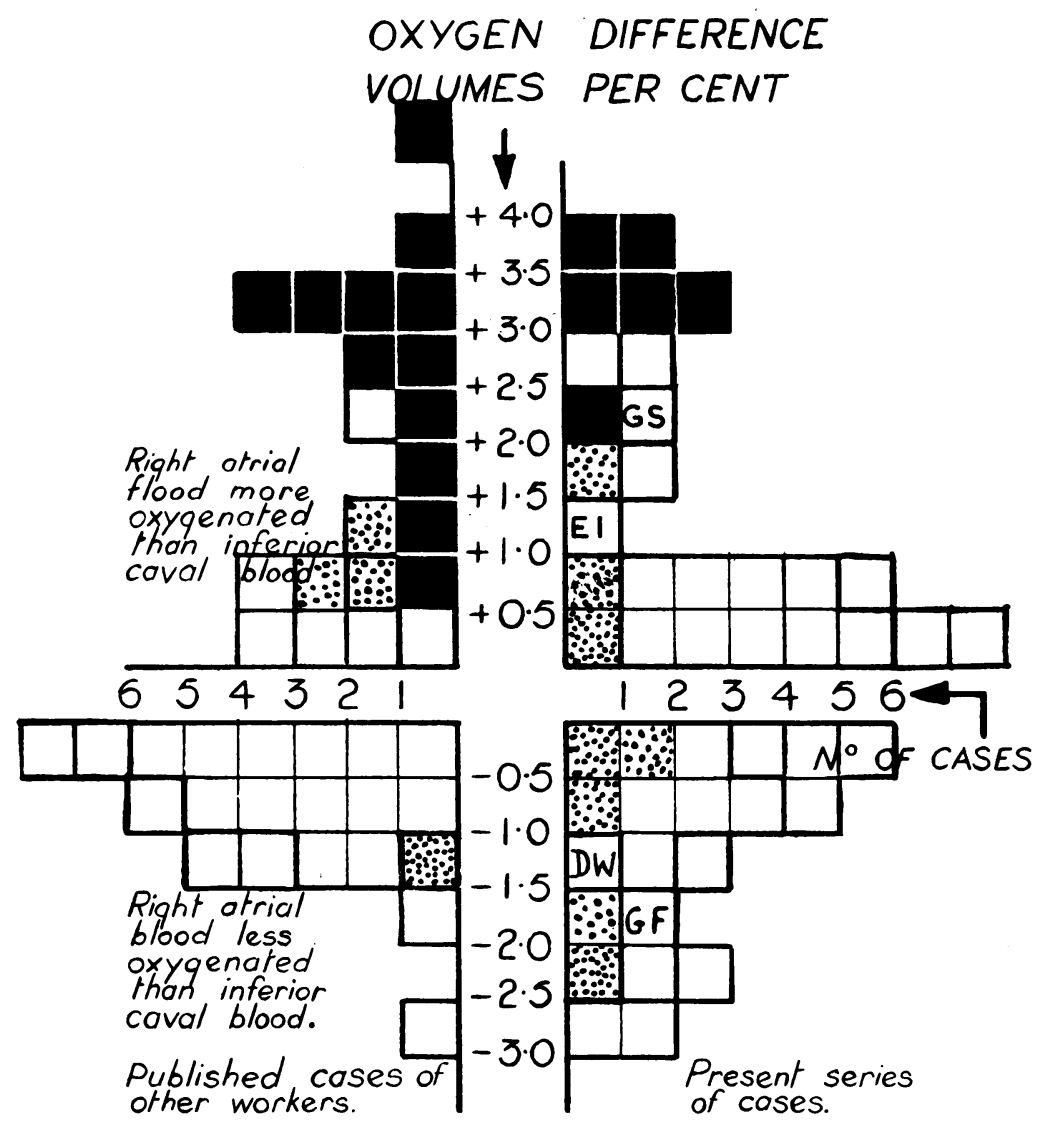

FIG. 2.-Differences in oxygen content (volumes per cent) of inferior vena caval and right atrial blood in 89 patients. White squares represent cases with no atrial septal defect, black squares cases with an atrial septal defect through which a predominantly arteriovenous shunt occurs, and stippled squares with an atrial septal defect through which a predominantly venoarterial shunt occurs.

more oxygenated than caval blood, in most cases by less than 1 volume per cent, and exceptionally by 1.5 volumes per cent. On the other hand, in 25 cases it was less oxygenated than atrial blood, in most cases by less than 1.5 volumes per cent, but exceptionally by as much as 2.5 volumes per cent. In all the cases of atrial septal defect with an arteriovenous shunt, the atrial blood was more than 2 volumes per cent higher in oxygen content than the mean of the superior and inferior caval bloods; so that taking the mean gives a better separation than if either the inferior or superior vena caval blood is used alone for comparison. In two of our cases, G. F. and D. W. (CB08 and O207) there was no reason to think that there was an atrial septal defect with an arteriovenous shunt. In these cases the right atrial blood sample was found to be 3.7 and 3.3 volumes per cent higher than that of the superior vena cava (Fig. 1), but in both the inferior vena caval blood had a considerably higher oxygen content than the atrial blood (Fig. 2). Fig. 3 shows that if the mean of the vena caval blood samples is taken in these two cases the oxygen difference between this and the right atrial blood falls within the range of cases without an atrial septal defect.

In Fig. 3 it is shown, as in previous figures, that when the shunt through an atrial septal defect is venoarterial the difference in oxygen content between caval and right atrial blood lies within the normal range. There is one exception in our cases, which was shown at necropsy to have an atrial septal defect so large that the two atria formed almost one chamber. 


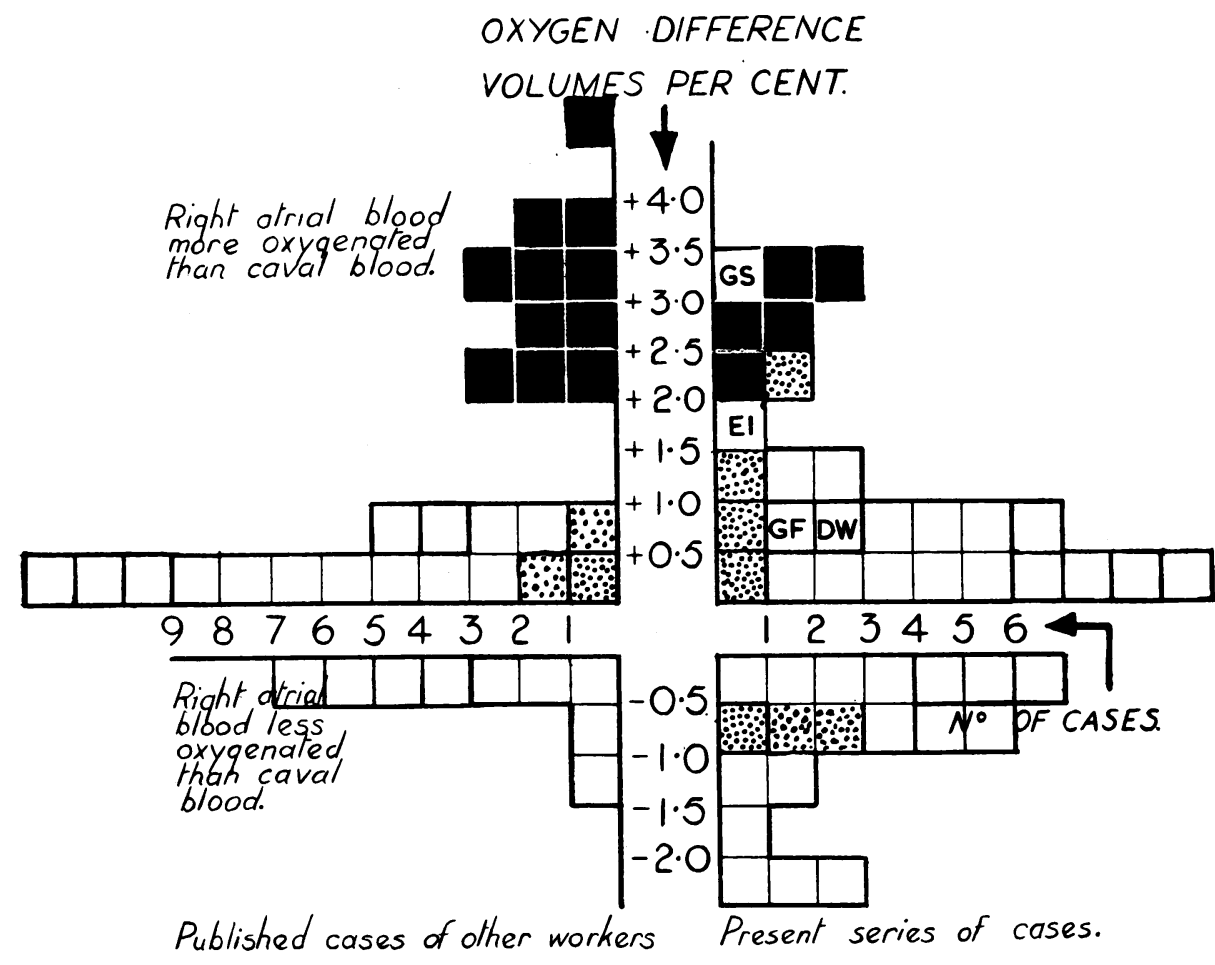

FIG. 3.-Difference in oxygen content between right atrial blood and the mean of the oxygen contents of the inferior and superior vena caval bloods in 84 patients. The white squares represent cases with no atrial septal defect, black squares cases with atrial septal defect through which a predominantly arteriovenous shunt occurs, and stippled squares cases with an atrial septal defect through which a predominantly venoarterial shunt occurs.

\section{Comparison of Right Atrial and Right Ventricular Blood Samples}

In Fig. 4 are shown the variations in oxygen content of right atrial and right ventricular blood in 49 cases considered to be without a ventricular septal defect and 98 with a presumed ventricular septal defect. In cases without ventricular septal defect the oxygen content of blood from the right ventricle may differ from that of the right atrium by \pm 1.0 volumes per cent, and seldom more. This finding is not unexpected since blood in the right atrium, derived from superior vena cava, inferior vena cava, and coronary sinus is not uniformly mixed. Warren et al. (1945) showed that samples of blood taken from the right atrium might differ in oxygen content by as much as 2.3 volumes per cent. On the other hand, the blood in the right ventricle is better mixed so that samples taken from different parts of the ventricle differ by less than 1.0 volumes per cent. It follows, therefore, that when comparing the oxygen contents of blood samples from the venæ cavæ and right atrium it is useful also to compare the oxygen content of the atrium against that of the ventricle. If this is done the finding of an oxygen content of blood in the right atrium higher than the mean of the oxygen contents of caval bloods may arise $(a)$ because the caval blood samples are not uniformly mixed and the catheter has withdrawn a sample derived mainly from the inferior vena cava, or $(b)$ because the catheter had withdrawn a sample derived from an influx of highly oxygenated blood from the left atrium. If the high oxygen is due to $(a)$ then the right ventricular blood should have a lower oxygen content than that of the atrial sample and should be about the mean of the caval samples. If the high oxygen content is due to $(b)$ then the ventricular sample should also have a higher oxygen content than the mean of the caval samples. There are exceptional cases which do not fit into this conception; for example in Case 2 (G. S., Fig. 1, 2, and 3) the right atrial sample 


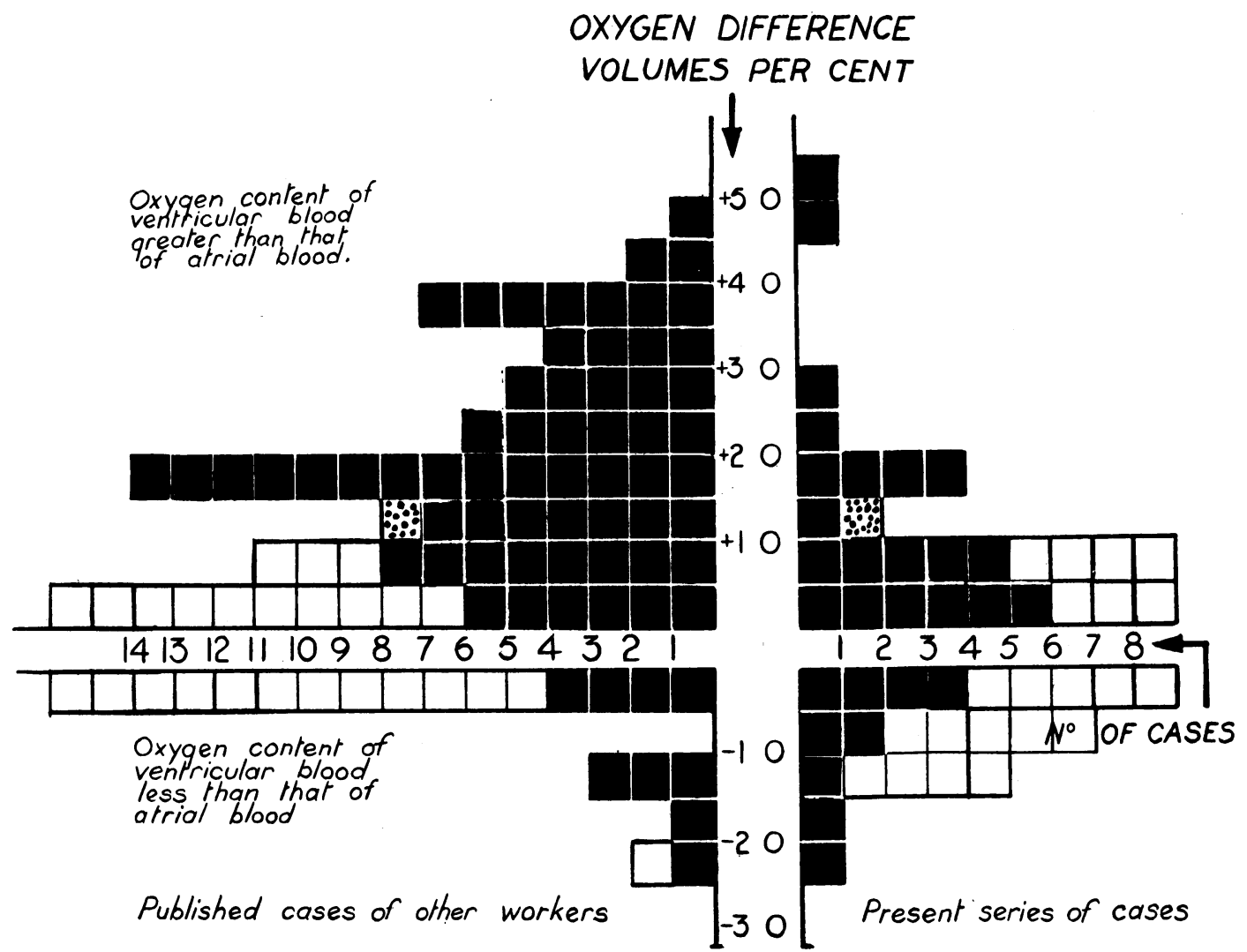

FIG. 4.-Difference in oxygen content (volumes per cent) between right atrial blood and right ventricular blood in 147 patients. The cases with ventricular septal defects are indicated by black squares, those with intact ventricular septums by white squares. The two stippled squares indicated that in two cases of patent ductus arteriosus in which probable pulmonary regurgitation had resulted in an increase in the oxygen content of right ventricular blood. The square indicating that the oxygen content of the ventricular sample was 2 to 2.5 volumes per cent less than the atrial sample represents a case of atrial septal defect in which the atrial sample had presumably been taken close to the defect.

was 3.5 volumes per cent higher than that of the mean of the caval blood samples and 2.5 volumes per cent higher than that of the inferior vena caval sample; this seems to point to an influx of blood through a septal defect. Nevertheless, the blood from the right ventricle was of considerably lower oxygen content than right atrial blood. A possible explanation of the case is that when the right atrial sample was taken the tip of the catheter lay close to a small atrial septal defect, and so withdrew blood of a high oxygen content. We have not been able to prove that such an atrial septal defect was present. In a second and similar case, E. I., with Fallot's tetralogy, the difference between caval and right atrial bloods was 1.7 volumes per cent, indicating a probable atrial septal defect (Fig. 3). In this case the right ventricular blood was nearer that of the atrium in oxygen content, which would also support the diagnosis of an atrial septal defect. However, at necropsy no atrial septal defect was found (Case P061). The explanation of these findings is unknown.

Of the 98 cases with a ventricular septal defect, the difference between right ventricular and right atrial blood oxygen content was greater in 55 than in cases without ventricular septal defect. It is clear, therefore, that only about one-half of the cases of ventricular septal defect can be recognized by a higher oxygen content of the ventricular blood. It is to be noted that this increase in oxygen content occurred in spite of the fact that in almost all these cases the predominant shunt was from right to left ventricle. This is because of turbulence in the neighbourhood of the defect. 
A high oxygen content of the right ventricular blood may be brought about not only by a septal defect, but also by regurgitation of blood through the pulmonary valves in cases of patent ductus arteriosus. This is clearly displayed by Cournand's (1949) Case 7, where the blood from the right atrium contained $10 \cdot 6$ volumes per cent oxygen, that from the right ventricle $12 \cdot 5$, and that from the pulmonary artery 14.2. After ligature of the ductus arteriosus the oxygen content of the right ventricle and pulmonary artery fell to the same level as that of the blood in the right atrium. The same phenomenon possibly accounts for the findings in the two cases of patent ductus arteriosus, indicated by stippled squares in Fig. 4, in which the oxygen content of the ventricular blood exceeded that of the atrial blood by 2.0 to 2.5 volumes per cent.

\section{Comparison of Right Ventricular and Pulmonary Blood Samples}

Fig. 5 shows the difference in oxygen content between right ventricular and pulmonary artery bloods in 82 patients. Thirty-three cases were considered to have neither ventricular septal defects

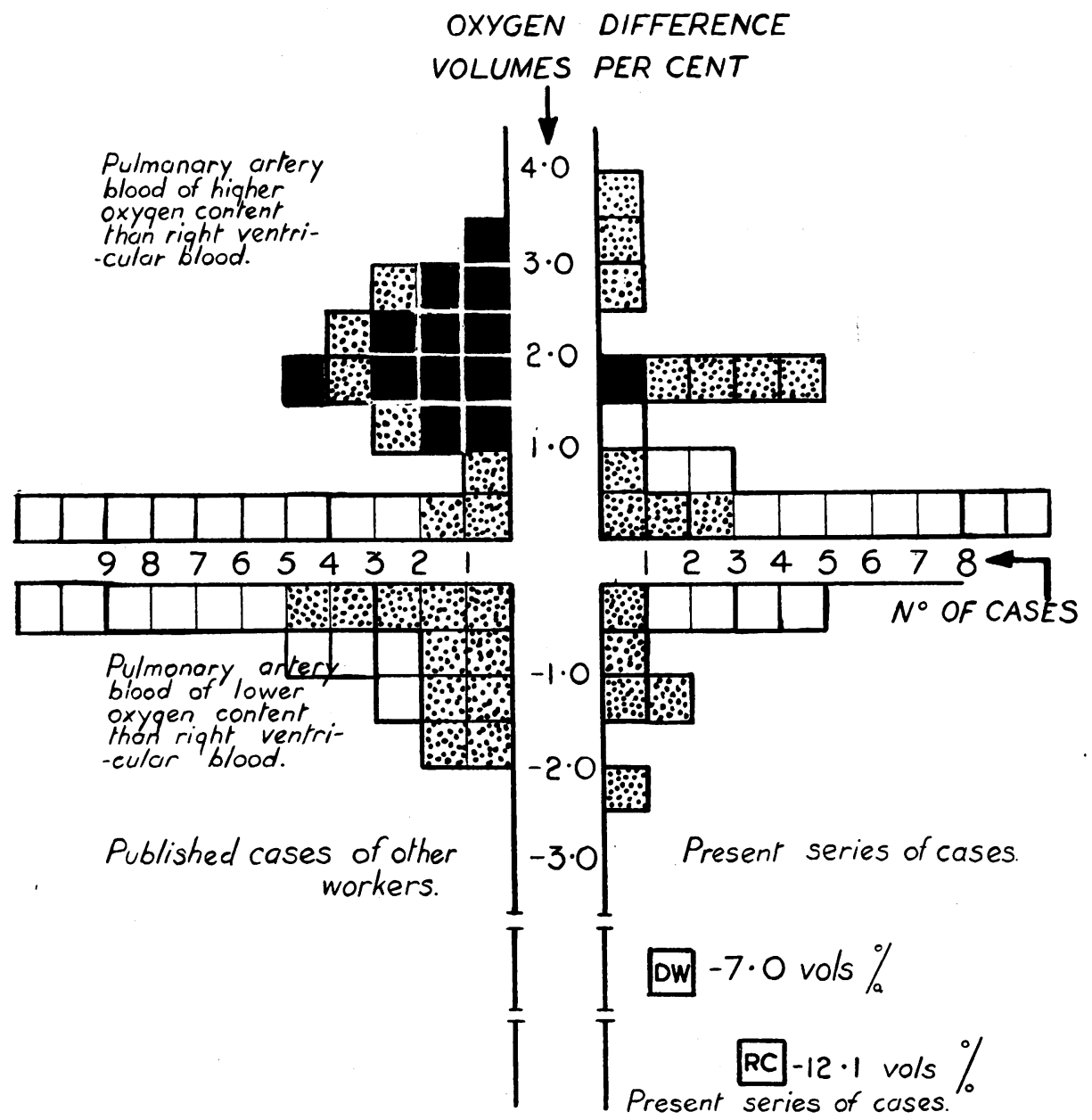

FIG. 5.-Difference in oxygen content (volumes per cent) of right ventricular and pulmonary artery bloods in 82 patients. White squares represent cases with no ventricular septal defect or patent ductus arteriosus, black squares represent cases with a patent ductus arteriosus, and stippled squares cases with a known ventricular septal defect. The significance of the two squares labelled D.W. and R.C. is given in the text. 
nor patent ductus arteriosus. In the large majority the oxygen content of the right ventricular and pulmonary artery bloods differs by no more than 0.5 volumes per cent, and in only two by little more than 1.0 volumes per cent. In all 13 cases with a patent ductus arteriosus the difference in oxygen content was more than 1 volume per cent. Of the 34 cases with a ventricular septal defect but no patent ductus arteriosus, there are 11 with the pulmonary artery samples more than 1 volume per cent higher than that of the right ventricle. The explanation of this is probably that the defect is high in the ventricular septum so that the mixture of blood occurred in the region of the infundibulum and not in the main chamber of the ventricle from which the sample was taken. Whatever the reason it is clear that a higher oxygen content of the pulmonary artery blood may arise either from a patent ductus arteriosus or a high ventricular septal defect. A third possible cause of the oxygen content of the pulmonary artery blood being higher than that of the ventricular blood is pointed out by Dexter (1947). If the catheter is pushed too far into the pulmonary artery it may occlude the branch in which it lies so that when a sample is withdrawn oxygenated blood is aspirated from the pulmonary capillaries. This may be the explanation of the high oxygen content of the pulmonary artery blood reported by Soulie et al. (1949) in two cases in which there was neither a patent ductus arteriosus nor a septal defect. For this reason all our samples from the pulmonary artery have been taken not further than one inch past the bifurcation.

There are 10 cases in which the oxygen content of the pulmonary artery blood is more than 1 volume per cent lower than that of the right ventricle. This is difficult to account for, but since all but one of these cases had pulmonary stenosis this may have been a factor. A further clue is given by considering the two cases D. W. and R. C., in which the pulmonary artery blood sample was as much as 7 and 12 volumes per cent lower than that of the right ventricle. In both these cases there was probably a very gross stenosis of the pulmonary artery because the catheter seemed to be gripped in the orifice, and when it was withdrawn a sense of release of grip was obtained. Also in another (Case 7), a sample taken when the catheter had been in the pulmonary artery about five minutes was 29 per cent saturated with oxygen, but after another minute or two a second sample showed the saturation to have fallen to 15 per cent. These findings suggest that the catheter had materially obstructed the pulmonary orifice, reducing the amount of blood passing through the lungs and exaggerating the venoarterial shunt, thus increasing the patient's anoxia. The patients made no complaint whilst the catheter was in the pulmonary artery, and the darkness of the X-ray room prevented us from seeing an increase in cyanosis.

\section{Calculation of Blood Flows and Shunts}

In normal hearts the cardiac output can be calculated with a fair degree of accuracy by the Fick principle, using the oxygen consumption and the difference in oxygen content of arterial and mixed venous blood. It is clear that in malformed hearts calculation may be liable to error because of the existence of shunts. Nevertheless, in most instances an estimate may be made of the blood flow through the pulmonary artery and through the aorta, and thus of the volume of any shunt present. The pulmonary blood flow is calculated from the oxygen consumption and the difference in oxygen content between pulmonary venous and pulmonary artery blood, aortic blood flow is calculated from the oxygen consumption and the difference in oxygen content of arterial and mixed venous blood. It is usually easy to obtain a satisfactory sample of arterial blood but in malformed hearts it is not always easy to obtain equally satisfactory samples of mixed venous or pulmonary artery blood.

Mixed venous blood. In a heart with no arteriovenous shunts the blood from the outflow tract of the right ventricle can be regarded as mixed venous blood. In many malformed hearts with which we have dealt, right ventricular blood is not acceptable as mixed venous blood because of admixture of oxygenated blood either in the atrium or ventricle. In only 6 of 18 cases shown in the appendix could the right ventricular blood be regarded as free from admixture with arterialized blood. When blood from the right ventricle cannot be accepted as mixed venous blood, most authors, and we ourselves, have used a blood sample from the right atrium, provided there was no 
evidence of an arteriovenous shunt through an atrial septal defect. If there was evidence of arterial admixture we have used the mean of the oxygen contents of the superior and inferior vena caval blood as representing that of mixed venous blood. This, however, is not altogether satisfactory because it is not known what volume each vena cava contributes to the blood entering the atrium, and the contribution to the mixed venous blood made by the coronary sinus and other veins entering the right atrium is neglected.

Pulmonary artery blood. Two factors may result in an unsatisfactory sample of blood being obtained from the pulmonary artery. If the catheter blocks the branch of the pulmonary artery in which it lies so that oxygenated blood is drawn from the lung capillaries the oxygen content of the blood sample will be unduly high. If the catheter obstructs even for a short time the stenosed pulmonary orifice the oxygen content of the sample of blood obtained may be unusually low. The presence of a ductus arteriosus makes it almost impossible to obtain a sample on which the estimation of the pulmonary blood flow can be reliably based. An approximation can be made by taking, as Cournand (1949) does, one sample from the artery and one from each main branch.

A further difficulty arises in many cases of suspected pulmonary stenosis when it is not possible to introduce the catheter into the pulmonary artery. In such cases blood from the right ventricular outflow tract is used as the best approximation. It is obvious from Fig. 5 that this would give rise to no great error, except when the ventricular septum is defective. For example, in Case 9, which showed the greatest difference between pulmonary artery and right ventricular blood $(+4$ volumes per cent) the pulmonary artery blood flow calculated on the pulmonary artery sample was 2 litres a minute per square metre, whereas when calculated on the right ventricular sample the pulmonary artery blood flow was 1.3 litres, or 35 per cent less. Apart from this case and those of patent ductus arteriosus, the two results never differed by more than 15 per cent when we have been able to calculate the pulmonary blood flow from both right ventricular and pulmonary artery samples. Even taking the higher of the two calculated flows the pulmonary blood flow in pulmonary stenosis was still reduced below normal.

Pulmonary venous blood. It is necessary in cases of cyanotic congenital heart disease to obtain evidence of the degree of saturation of the blood in the pulmonary veins, for though in patients with normal hearts it may be accepted that arterial blood gives a measure of pulmonary vein blood saturation, in cases of malformed hearts with a venoarterial shunt this assumption cannot be made. Bing et al. (1947) in 4 cases of Fallot's tetralogy obtained blood from a pulmonary vein by passing a catheter through an atrial septal defect and in each case the pulmonary vein blood was 95 per cent saturated. A few other isolated case reports have since been published which agree with this finding, and we have obtained pulmonary venous blood in 5 cases, either through an atrial septal defect or from a pulmonary vein draining into the right atrium. In each case we have found it to be 95 to 97 per cent saturated. None of these had signs of congestive failure or of pulmonary disease, either of which might have interfered with oxygenation of blood in the lungs; all had polycythemia, a factor that in the past has been thought to result in impaired oxygenation of blood passing through the lungs. It seems justifiable to conclude that in cases of congenital heart disease, provided that there is no congestive failure or pulmonary disease, the blood becomes 95 per cent saturated in passing through the lungs.

The Application of Cardiac Catheterization to the Diagnosis of Congenital Heart Disease

Fallot's tetralogy. The success of the operative treatment of Fallot's tetralogy has led to emphasis of the physiological features of the malformation (reduced pulmonary blood flow and venoarterial shunt) rather than the four anatomical features described by Fallot.

Operative treatment is directed towards increasing the blood flow through the lungs which is reduced by the pulmonary stenosis. Before operation one should, therefore, know that the pulmonary blood flow is in fact reduced below the normal. In the majority of cases clinical methods suffice to establish this, but there remain a few in which the reduction of the pulmonary blood flow 
is in doubt. It is to be remembered that slighter degrees of stenosis of the pulmonary orifice do not necessarily result in a materially reduced pulmonary blood flow (see Case 5).

Cardiac catheterization can demonstrate the pulmonary stenosis by showing a reduction in blood pressure as the catheter tip passes from the right ventricle into the pulmonary artery (Fig. 6). By correlating the position of the catheter tip with the changes in pressure it can sometimes be shown whether the stenosis is at the pulmonary valves or in the infundibulum.

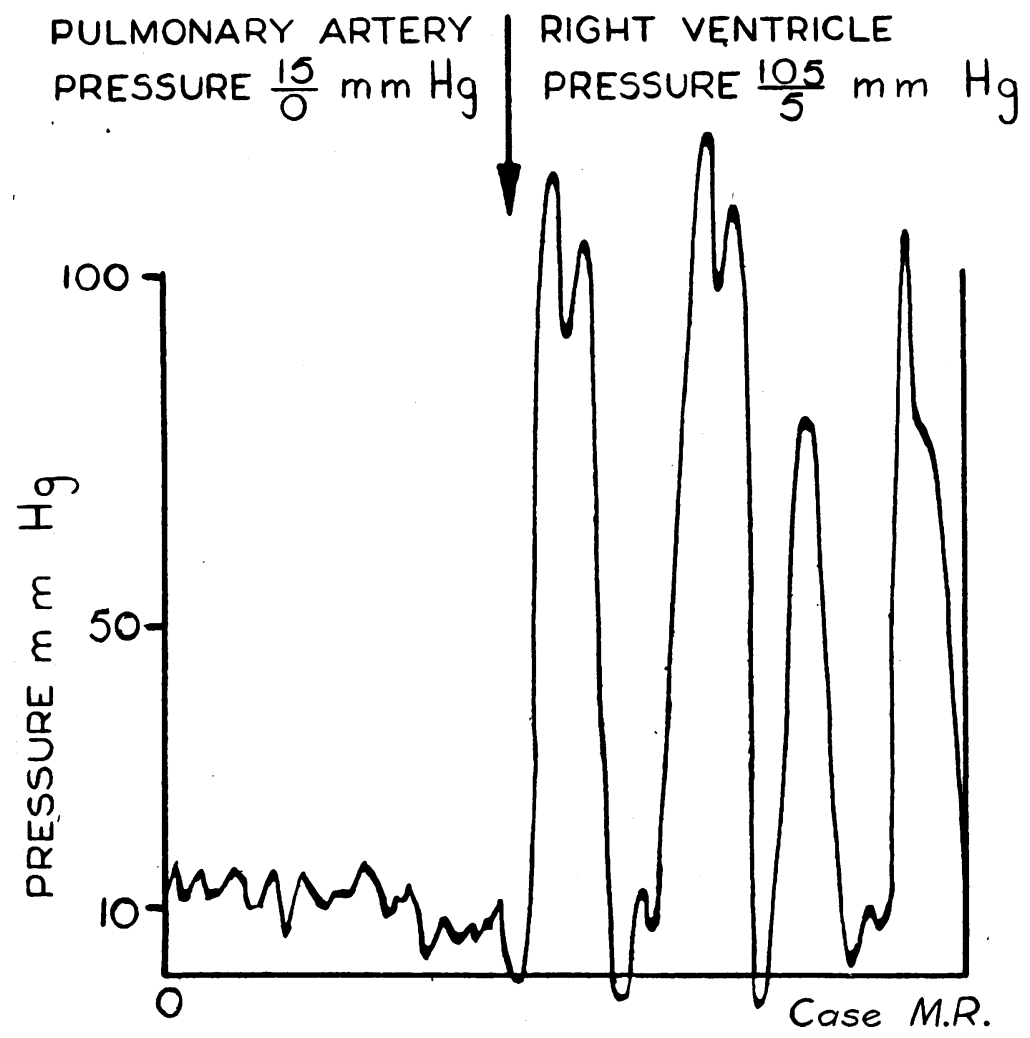

Fig. 6.-Tracing of pulse curve obtained on withdrawing the catheter through a pulmonary stenosis into the right ventricle. Case 3 (0051).

In our own experience, and that of other workers, catheterization directly demonstrates the stenosis in only about one-half of the cases of Fallot's tetralogy. In the other half of the cases it has not been found possible to catheterize the pulmonary artery, seldom because the stenosed ostium is too narrow but, as judged by the position of the catheter on the X-ray screen, because its tip is caught up by the muscle ridge surrounding an infundibular stenosis, or by the hypertrophied papillary muscles. In such cases the finding of a high pressure in the ventricle is not sufficient evidence on which to base a diagnosis of pulmonary stenosis, for this may occur in the absence of obstruction to the pulmonary orifice as, for example, in such conditions as patency of the ventricular septum, Eisenmenger's syndrome, or transposition of the great vessels. Estimation of the pulmonary blood flow, using the right ventricular sample of blood, may show whether the pulmonary blood flow is materially reduced. We have pointed out, however, that for various reasons this calculation is only approximate.

In a few cases dextroposition of the aorta can be demonstrated by passing the catheter through into it from the right ventricle (Fig. 8). Usually, however, the catheter passes into the pulmonary artery. The venoarterial shunt, resulting from the dextroposition, is shown by the lowered oxygen 
saturation of the arterial blood. An approximate estimation of the volume of the shunt can be made by subtracting the pulmonary from the systemic blood flow.

For the selection of cases for operation, Taussig (1948) stresses the importance of showing a reduced pulmonary blood flow. From our own experience, however, the demonstration of a lowered arterial oxygen is of equal importance because the lower the saturation of the arterial blood the more useful will be its circulation through the lungs. For example, in a case of pulmonary stenosis with a very small septal defect, such as Case 6 , with an arterial saturation of 91 per cent and a much reduced systemic blood flow, recirculation of the already arterialized blood through the lungs could improve the saturation but little. Moreover, it might be harmful to reduce further the systemic blood flow by diverting blood through the lungs.

Examples of the findings at catheterization in four cases of Fallot's tetralogy are given in the appendix (Cases 1, 2, 3, and 4).

\section{Eisenmenger's Complex}

Eisenmenger's complex consists of a high ventricular septal defect with an aorta that overrides the right ventricle, and a pulmonary artery that may be dilated. Though much less common, this condition is important because it may, be confused clinically with Fallot's tetralogy. It differs from this, however, in that there is no pulmonary stenosis and little or no reduction in blood flow to the lungs. The operation of systemic-pulmonary anastomosis is therefore unlikely to help the patient.

Catheterization clearly excludes pulmonary stenosis by showing equal systolic pressures in right ventricle and pulmonary artery (Fig. 7). There should be no gross reduction in the pulmonary blood supply.

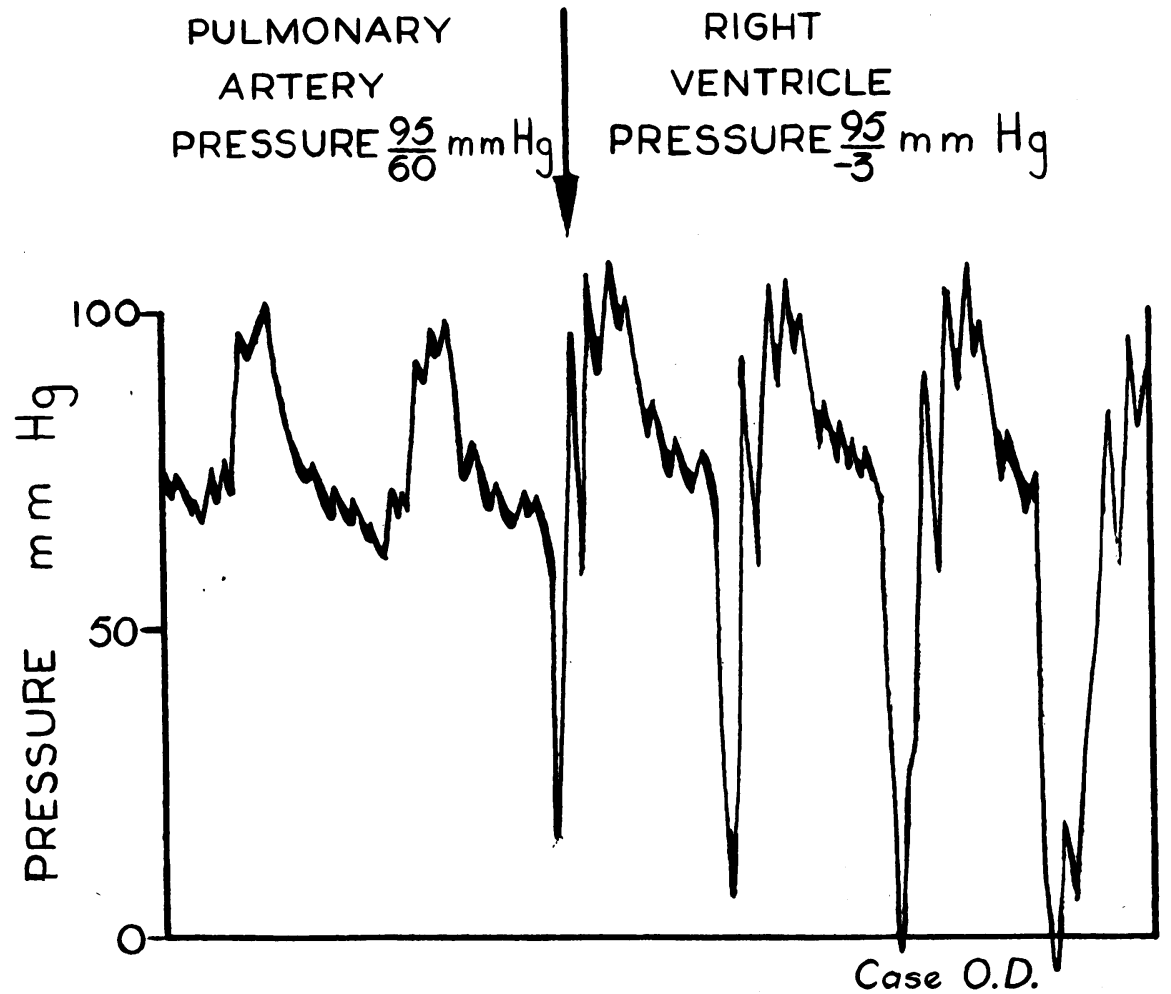

Fig. 7.-Pulse curve obtained in a case of Eisenmenger's syndrome on withdrawing the catheter from the pulmonary artery into the right ventricle. Case 9 (O261). 
In Case 3 (see appendix) it was difficult on clinical grounds to know if the increased pulmonary shadows indicated Eisenmenger's complex or an increased collateral circulation. Cardiac catheterization, however, showed a pulmonary stenosis. The calculated pulmonary blood flow was $2 \cdot 6$, and the systemic blood flow $4 \cdot 3$ litres per square metre a minute. The reduction in pulmonary blood flow was therefore small, though there was no doubt about the pulmonary stenosis.

Eisenmenger's complex is generally regarded as a malformation distinct from transposition of the great vessels. There is evidence, however, to show that the effect upon the circulation is the same in the two conditions. In one (Case 9) of our cases of Eisenmenger's complex we were able to pass the catheter into the pulmonary artery. The oxygen content of the blood sample withdrawn from it was higher ( 25.6 volumes per cent) than that from the right ventricle ( 21.6 volumes per cent), thus showing that the pulmonary artery received blood from both ventricles. The reduced arterial saturation showed that the aorta also received blood from both ventricles. Analysis of the data given by Bing (1947b) for four cases of Eisenmenger's complex shows that in three the oxygen content of the pulmonary artery blood was, as in our case, higher than that in the right ventricle and that the arterial oxygen saturation was reduced. Eisenmenger's complex may therefore be regarded as in effect a functional form of transposition of the great vessels.

A point of interest may be noted in passing. Bing (1947) finds that in all four of his cases the diastolic pressure in the pulmonary artery was raised, and this, together with a nearly normal blood flow through the lungs, points to an increased resistance in the pulmonary vascular bed. Fig. 7 shows the high diastolic pressure in the pulmonary artery in our Case 9. In this instance the calculated pulmonary blood flow was $2 \cdot 1$ litres per square metre a minute. The cause of this increased resistance is not known, though Bing seems to suggest that it is due to an endarteritic change in the pulmonary arterioles. In other conditions, however, in which the pulmonary vascular bed is subjected to a high blood pressure (transposition of great vessels and widely patent ductus arteriosus) the pulmonary blood flow is often increased and not reduced.

\section{Transposition of the Great Vessels}

Catheterization is of great value in establishing the diagnosis of transposition of the great vessels since only by this means can it be shown that the blood in the pulmonary artery is of higher oxygen content than blood in the aorta. Also, an estimation can be made of the relative amounts of right ventricular and left ventricular blood entering the two great vessels. In two of our four suspected cases the catheter passed, from the right ventricle into the aorta but could not be inserted into the pulmonary artery (Fig. 8). In these two cases, therefore, catheterization did not establish the diagnosis of transposition of the great vessels. One of them, thought clinically to be a case of Fallot's tetralogy, later came to necropsy, and transposition with stenosis of the pulmonary artery was revealed (Case P088); in the other transposition of the aorta and pulmonary artery was suspected on clinical grounds and confirmed by angiocardiography (Case O052). In the other two of our four (Cases 10 and 11) the catheter passed from the right ventricle into the pulmonary artery and not into the aorta. Transposition was shown by the finding that the pulmonary artery blood was more oxygenated than that in the systemic arteries. The calculated pulmonary blood flow in both these cases was greater than normal (5.1 and 8.3 litres per square metre a minute) and the pressure in the pulmonary artery increased $(88 \mathrm{~mm}$. $\mathrm{Hg}$ mean pressure and $80 / 50 \mathrm{~mm} . \mathrm{Hg}$ respectively).

\section{Pulmonary Stenosis with Closed Ventricular Septum}

This condition has been termed " pure pulmonary stenosis," but for reasons discussed by Allanby and Campbell (1949) the term " pulmonary stenosis with closed ventricular septum" is to be preferred. In most cases there is a defect of the atrial septum through which a venoarterial shunt occurs, though some are entirely without septal defects. There is no difficulty in recognizing the pulmonary stenosis, clinically or by the pressure readings during catheterization of the pulmonary artery, or.indirectly by calculation of the pulmonary blood flow. A case with no atrial septal defect, 
and therefore no venoarterial shunt, is readily recognized by the normal arterial oxygen saturation (Case 5), even though the greatly reduced cardiac output may be associated with a high degree of peripheral cyanosis (Case 6).

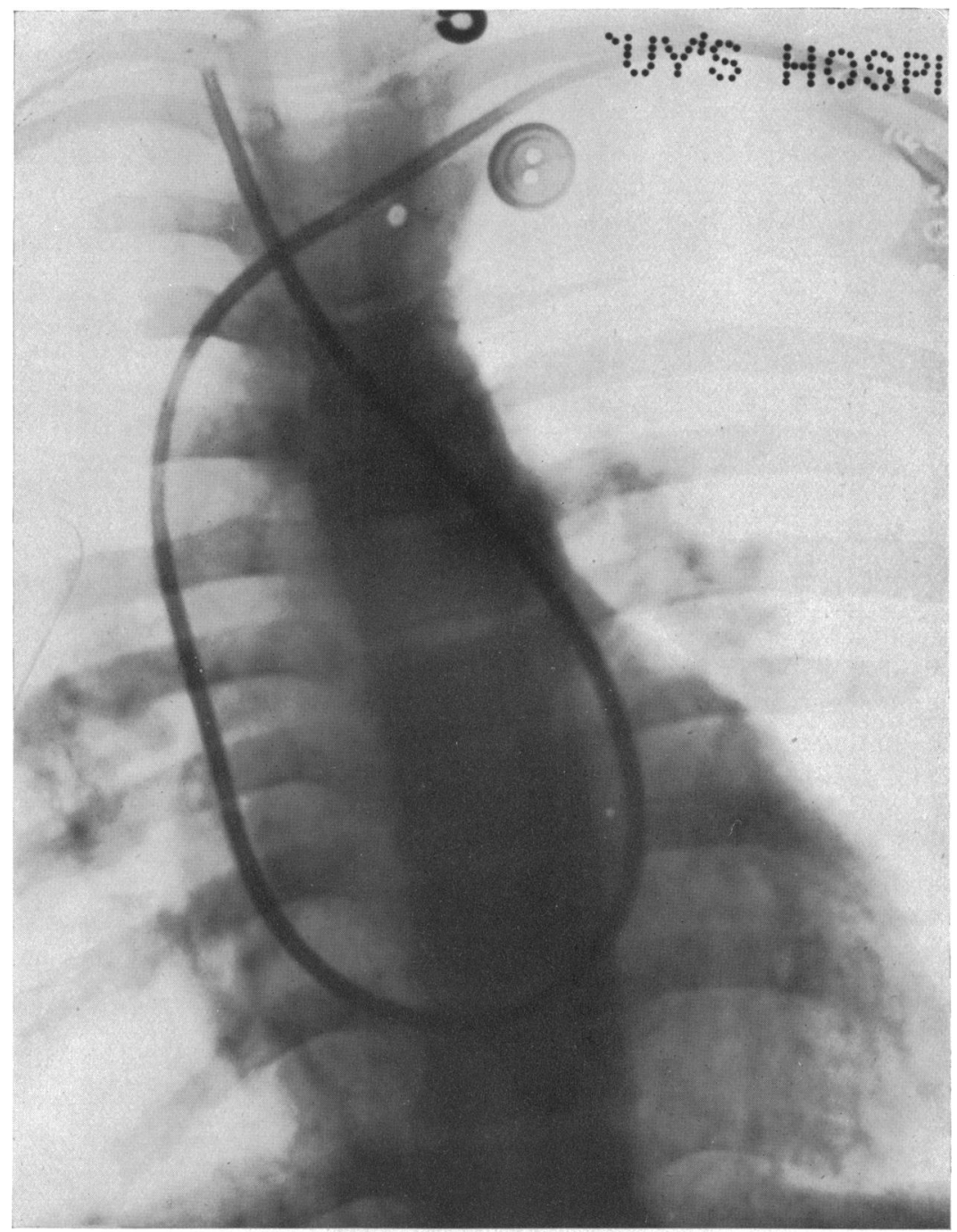

Fig. 8. - Passage of the catheter from the right ventricle into the carotid artery in a case of transposition of the great vessels with right-sided aortic arch. Reference No. 0052.

There are patients in whom it is difficult to decide whether the venoarterial shunt occurring with a pulmonary stenosis passes through a ventricular septal defect (Fallot's tetralogy) or through a defect of the atrial septum (pulmonary stenosis with closed ventricular septum) or through both. Unfortunately cardiac catheterization often fails to make the differentiation (see Case 8). The defect, generally a patent foramen ovale, is small in these cases and there is no record of it having been recognized by passing the catheter through it into the left atrium. It has also been shown (Fig. 1, 2, and 3) that an atrial septal defect with a venoarterial shunt can very seldom be recognized by the comparison of the oxygen content of atrial and vena caval bloods. Catheterization, there- 
fore, in pulmonary stenosis with closed ventricular septum and atrial septal defect is unlikely to demonstrate the atrial septal defect, but the latter may be inferred when the venoarterial shunt is found to be small. Of those cases of the group that have a ventricular septal defect, only one-half may be expected to be diagnosed by the increase in oxygen content on passing from atrium to ventricle (Fig. 4). In the absence of a patent ductus arteriosus the ventricular septal defect may also be shown by the increase in oxygen content on passing from the right ventricle to the pulmonary artery (Fig. 4 and Case 4). The position of the stenosis can be judged on the X-ray screen by the position of the catheter tip when the abrupt increase in pressure occurs between the pulmonary artery and the right ventricle as the catheter is withdrawn. If the change is seen to take place high in the pulmonary conus it is in favour of a valvular or high infundibular stenosis, and if low in the pulmonary conus in favour of a lower infundibular stenosis. Since a valvular stenosis occurs more frequently with a closed ventricular septum, and an infundibular stenosis with a ventricular septal defect the position of the stenosis may provide a further aid to diagnosis.

Whether the septal defect in these cases is atrial or ventricular is, however, not of great surgical importance. The practical point is to decide on the relative volumes of the cardiac output and venoarterial shunt, for the smaller the venoarterial shunt the more is valvulotomy to be preferred to systemic-pulmonary anastomosis.

\section{Atrial Septal Defect}

The shunt through an atrial septal defect is always arteriovenous when the lesion is an isolated one or associated with mitral stenosis (Bedford et al., 1941; Brannon et al., 1945; Cournand, 1947). When, however, the atrial septal defect is associated with other cardiac malformations the shunt through it is usually venoarterial. To account for the reversal of the direction of the intra-atrial shunt (as, for example, in pulmonary stenosis with closed ventricular septum) a fall in the left atrial pressure must be inferred, since measurements show no increase in right atrial pressure. Such a reduction in pressure might result from the diminished pulmonary venous return.

An atrial septal defect can sometimes be recognized by passing the catheter through the defect. Even a direct demonstration of a septal defect does not prove that there is normally a shunt as it may be a patent foramen ovale normally covered by a valve; it is still desirable to show by blood oxygen comparisons that a shunt occurs through it. The course of the catheter passing through an atrial septal defect is characteristic (Fig. 9), crossing to the left at a higher level than when going through the tricuspid valve. The catheter tip can sometimes be advanced into a pulmonary vein, the catheter then leaving the heart shadow. Confirmatory evidence is the high oxygen saturation of the blood obtained from the left side of the heart. When the catheter cannot be passed through the atrial septal defect a comparison of the oxygen content of the vena caval and atrial bloods will reveal the presence of the defect if an arteriovenous shunt occurs, but not if the shunt is venoarterial.

With an arteriovenous shunt through an atrial septal defect, the right heart output and pulmonary blood flow are increased, the pulmonary blood flow being as much as 5 times increased (Taylor et al., 1948, Case 6). In such cases, in spite of the large amount of blood passing through the atrial septal defect into the right atrium, the right atrial pressure is rarely raised above normal. Right ventricular and pulmonary artery pressure may be slightly raised but occasionally may be much increased (Dexter, 1947, Case 1, and Taylor et al., 1948, Case 3). The systemic blood flow, calculated from the mean of the oxygen contents of the superior and inferior venæ cavæ, is not reduced.

It should be noted that a number of malformations may also give rise to increased oxygen content of the right atrial blood and so lead to the suspicion of an atrial septal defect. The most frequently encountered (three times in our series) is the opening of an anomalous pulmonary vein directly into the right atrium. Until recently this condition has been recognized only after death (Brody, 1942; Taussig, 1947) but Cournand et al. (1949) have described one case diagnosed during life. In Cournand's, as in our three cases, this was shown when the catheter slipped from the atrium into a pulmonary vein of the right lung (Fig. 10). We have verified the location of the tip by 


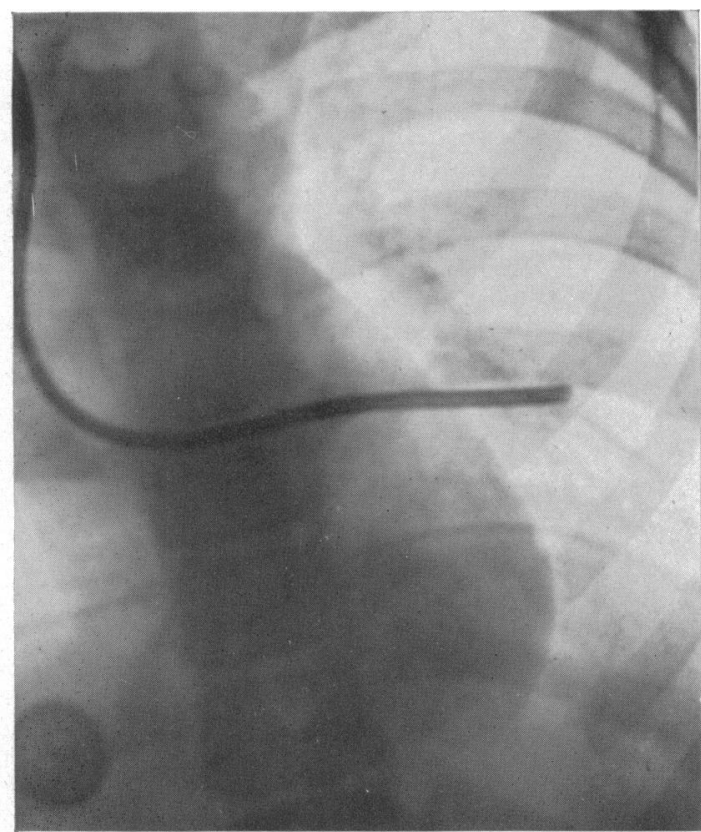

FIG. 9.- Passage of the catheter through an atrial septal defect and into a left pulmonary vein. The catheter passes from the right atrium over to the left side of the heart at a higher level than when passing into the right ventricle. Reference No. P021.

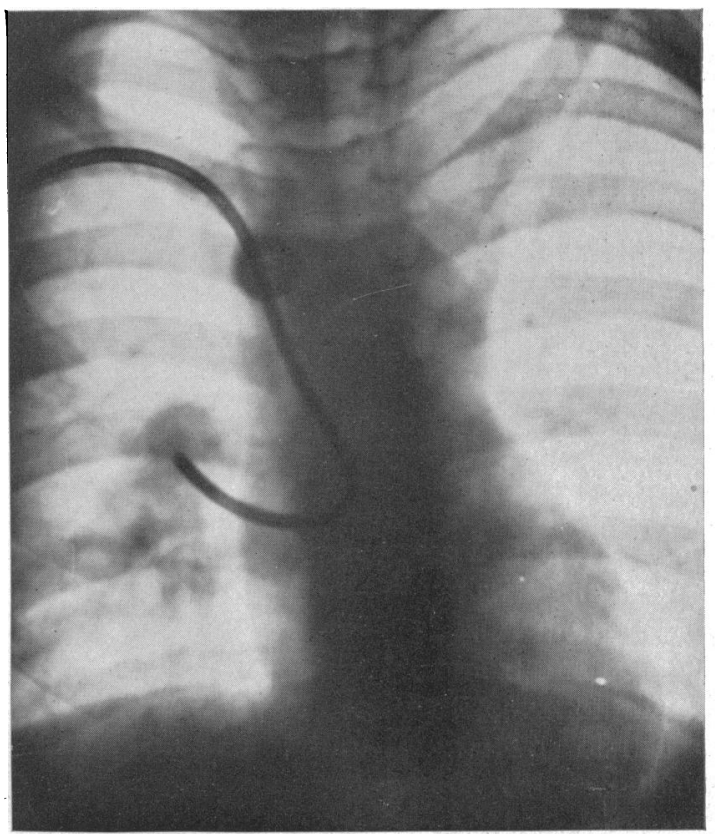

FIG. 10.-Passage of the catheter from the right atrium into a pulmonary vein which opens directly into the atrium. Reference No. P021.

screening in the oblique position and by drawing arterialized blood from the catheter. In two of the three patients an atrial septal defect was also demonstrated. The other and rarer conditions which we have not encountered personally are (1) an arteriovenous fistula between a coronary artery and the coronary sinus, (2) tricuspid insufficiency associated with a ventricular septal defect, (3) pulmonary and tricuspid valve insufficiency in the presence of a patent ductus arteriosus, (4) a congenital communication between the left ventricle and the right atrium (Perry et al., 1949), and (5) a persistent common atrio-ventricular ostium.

\section{Lutembacher's Syndrome}

The association of an atrial septal defect with mitral stenosis was first described by Lutembacher (1916). The clinical diagnosis of the condition usually presents no difficulties, but doubt may arise whether mitral stenosis is present in a case of atrial septal defect, or whether an atrial septal defect is present in a case of mitral stenosis.

There is yet insufficient evidence to show how far catheterization can assist in the diagnosis of Lutembacher's syndrome. So far as we are aware no catheterization findings have been reported in this condition. Among Brannon et al. (1945) cases of atrial septal defect there is, however, one (Case 8) described as having a low-pitched rumbling diastolic murmur at the apex of the heart which, though the authors do not refer to it, may be an instance of Lutembacher's syndrome. We ourselves have one example (Case 17) in which mitral stenosis was recognized by the characteristic murmur and clinical evidence of atrial septal defect was also present; on catheterization proof of an atrial septal defect consisted in the passage of the catheter through the defect into the left atrium, and the finding of blood of a high oxygen content in the right atrium. In both these cases right atrial, ventricular, and pulmonary artery pressure were raised well above normal. These findings are to 
be expected from the combination of mitral stenosis and atrial septal defect. In our patient the systemic flow, calculated from the mean oxygen content of the superior and inferior vena caval bloods was considerably reduced, but was normal in the case of Brannon et al. There is as yet no necropsy confirmation of the condition in either of these.

Whilst the findings obtained in these two cases were to be expected in Lutembacher's syndrome, there is some doubt whether they are diagnostic because some instances of atrial septal defect without a suggestion of mitral stenosis have been reported with markedly raised pressures in the right ventricle and pulmonary artery (Dexter et al., 1947, Case 1, and Taylor et al., 1948, Case 3). This rise of pulmonary arterial pressure is unusual in uncomplicated atrial septal defect, and in the discussion Dexter and Taylor do not consider the possibility of mitral stenosis having been present. Whilst a reduced systemic blood flow would be in favour of mitral stenosis, a normal systemic blood flow would not exclude the condition.

\section{Tricuspid Atresia and Pulmonary Atresia}

In tricuspid atresia the blood passes from the right atrium through a septal defect into the left atrium and ventricle, and thence directly or indirectly into the pulmonary artery and aorta. In pulmonary atresia the blood reaches the lungs through either a patent ductus arteriosus or from dilated bronchial vessels arising from the aorta. In both tricuspid and pulmonary atresia there may be a small right ventricle. The two abnormalities are considered together since they resemble each other functionally and in both blood for the pulmonary and systemic circulations is derived from the left ventricle. In a patient with the signs and symptoms of Fallot's tetralogy, an electrocardiogram showing left ventricular preponderance is thought to be diagnostic of tricuspid atresia, and angiocardiograms show the abnormal path of the blood through the heart (Campbell and Hills, 1950). On catheterization, the catheter may be seen not only to pass through the atrial septal defect but also to pass into the left ventricle (Case 13, Fig. 11 and 12). Catheterization cannot, however,

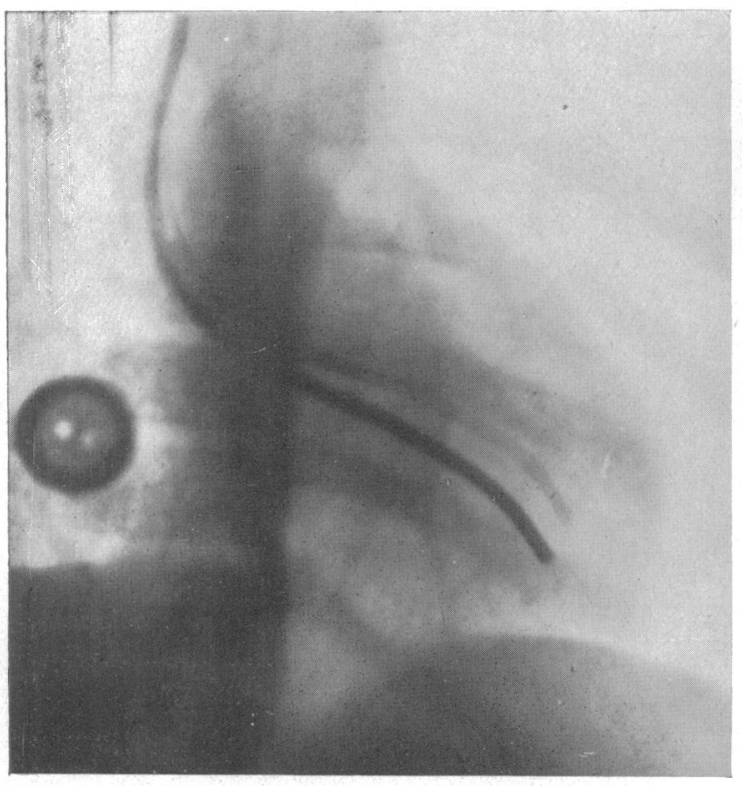

FIG. 11.-Passage of the catheter through an atrial septal defect and into the left ventricle. Antero-posterior and right lateral views. Case 13 (O229).

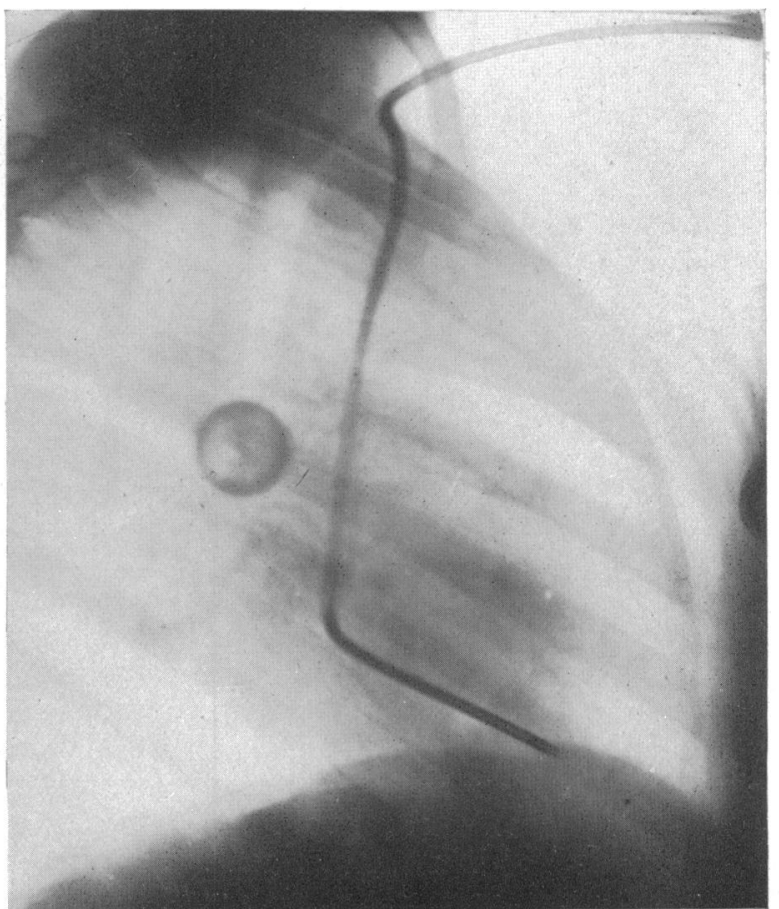


RIGHT ATRIUM

PRESSURE $\frac{10}{0} \mathrm{~mm} \mathrm{H}$.

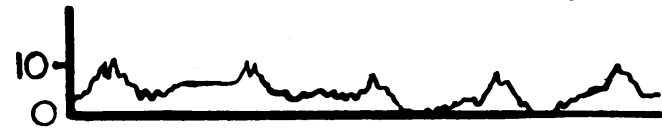

? CORONARY SINUS

PRESSURE $\frac{62}{16} \mathrm{~mm} \mathrm{Hg}$

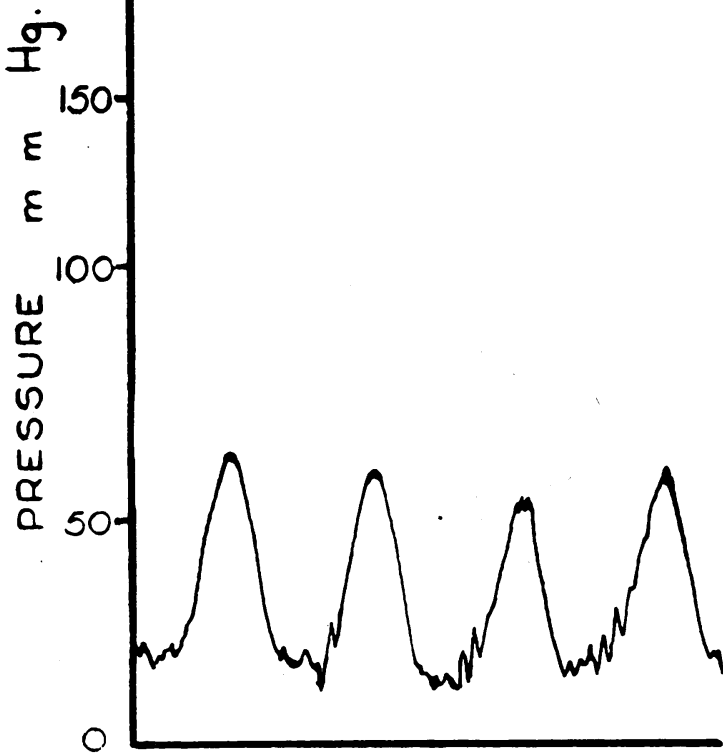

LEFT ATRIUM

PRESSURE $\frac{10}{0} \mathrm{~mm} \mathrm{Hg}$.

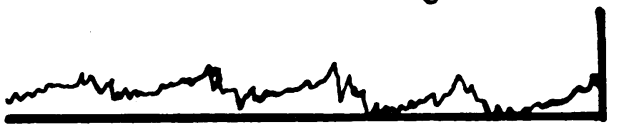

LEFT VENTRICLE

PRESSURE $\frac{160}{20} \mathrm{~mm} \mathrm{Hg}$.

Fig. 12.-Pressure tracings obtained from the right atrium, ? coronary sinus, left atrium, and left ventricle in Case $13(\mathrm{O} 229)$.

distinguish between tricuspid atresia and pulmonary atresia, except in those instances when the catheter is passed from the right atrium into the right ventricle, as, for example, the case reported by Geraci et al. (1948).

It is generally assumed that the pulmonary blood flow is reduced, and on this assumption pulmonary systemic anastomosis is carried out with apparent benefit (Potts and Gibson, 1948; Baker et al., 1949; Soulie et al., 1949). The pulmonary blood flow can be calculated if we assume complete mixing of the blood in the left ventricle so that the oxygen content of blood supplied to the lungs can be taken as that of the arterial blood. In 7 of our 9 cases diagnosed on clinical grounds the calculated pulmonary blood flow was decreased ( 1.2 to 2.5 litres per square metre a minute) but in two slightly increased (3.4 and 3.9 litres per square metre a minute). So far only those of our patients with reduced pulmonary blood flow have been operated on. Operation has been delayed on the two cases with increased blood flow because they have a fairly good exercise tolerance. In most of the accounts given by others data are wanting on which pulmonary blood flow can be 
calculated so it is not known whether the successful operations include any in which the pulmonary blood flow was increased. Geraci et al. (1948) give the data from two adults, one with tricuspid and the other with pulmonary atresia, from which the pulmonary blood flow can be calculated and shown to be increased. Whether operation was carried out on these two is not recorded, but both are noted to have relatively good exercise tolerances.

That the pulmonary blood flow may be increased or decreased is not unexpected in view of the necropsy findings. In tricuspid atresia the pulmonary artery may arise directly from the left ventricle and if this occurs, as Taussig (1948) points out, increased pulmonary blood flow will be likely. In most cases, however, there is some obstruction to the pulmonary flow.

\section{Truncus Arteriosus and Pulmonary Atresia}

Under this heading we are discussing the malformations in which the blood supply to both pulmonary and systemic circulations is derived from a single great vessel which overrides both ventricles. This condition may be either a true truncus arteriosus, or the vessel may be the aorta, in which case an atresic pulmonary artery can be found post-mortem. The diagnosis of these two conditions is difficult to establish by any method and, except at necropsy, the differential diagnosis between them is presumptive. Clinical and X-ray examinations may suggest the condition and angiocardiography and cardiac catheterization may support the diagnosis.

Since the blood supply to the lungs is of the same oxygen content as that of arterial blood it is possible without catheterization to calculate the pulmonary blood flow from the oxygen content of the arterial blood. In three cases where the diagnosis was confirmed (at necropsy in two and at operation in the third), the pulmonary blood flow was thought to be slightly increased in one (3.8 litres) and slightly decreased in the other two (2.5 and 2.0 litres per square metre a minute). The presumed diagnosis of truncus arteriosus in the two catheterized cases has not yet been confirmed. Assuming the diagnosis to be correct, the calculated pulmonary blood flow was normal in one (Case 12); in the other, again assuming the diagnosis, the calculated pulmonary blood flow is about three times the normal. Since the X-ray appearances of the lungs suggest a decreased rather than an increased blood flow, this finding is against the clinical diagnosis.

\section{Patent Ductus Arteriosus}

In patent ductus arteriosus, arterial blood flows from the aorta to the pulmonary artery and so an increase in blood oxygen content is found on passing from right ventricle to pulmonary artery. Such an increase in oxygen content may be brought about in several ways (see section on comparison of right ventricular and pulmonary artery bloods) so that confirmatory evidence is required before patent ductus arteriosus can be diagnosed on the grounds of oxygen differences. We have found the characteristic murmur to be the most satisfactory indication of a patent ductus, though proved cases have occurred that do not present this sign.

In most instances of patent ductus arteriosus the pulmonary artery pressure is within normal limits, but in some it is increased. Dexter (1947) found it increased in three of twelve cases. In contrast to Eisenmenger's syndrome (Case 9 and Bing, 1947) in which an increased pulmonary artery pressure was associated with a reduced pulmonary blood flow, the calculated pulmonary blood flow in the three cases was increased $(16.9,14 \cdot 2,8 \cdot 8$ litres per square metre a minute). This finding indicates that increased pulmonary artery pressure is not always associated with a marked increase in pulmonary vascular resistance.

\section{Pulmonary Arteriovenous Fistula}

The symptoms and some of the signs of pulmonary arteriovenous fistula are so similar to those of congenital heart disease that the condition should be mentioned here. Catheterization does not help in the diagnosis but is useful for assessing the volume of the shunt. From the oxygen saturation of the arterial blood the proportion of the total blood stream passing through the fistulæ can 
be calculated, but to calculate the actual blood flows mixed venous blood must be obtained by catheterization (Case 18).

\section{General Remarks}

The information that cardiac catheterization can afford in the diagnosis of congenital heart disease has been discussed under the heading of the different malformations. It remains to compare briefly the diagnostic aid to be obtained from cardiac catheterization and angiocardiography, and to state in general terms the value of the former.

Both cardiac catheterization and angiocardiography are proving valuable, the more so because their findings are often complementary. Angiocardiography gives more anatomical, cardiac catheterization more physiological information. Cardiac catheterization gives an indication of the necessity for surgical measures and whether a pulmonary-systemic anastomosis or a valvulotomy operation would be more useful. Angiocardiography is useful, particularly from the surgeons' point of view, in demonstrating the disposition of the great vessels. Angiocardiography is more useful in showing shunts when they are venoarterial whereas cardiac catheterization more surely demonstrates arteriovenous ones. For example, in tricuspid atresia angiocardiography would show the atrial shunt that might escape the cardiac catheter; but in uncomplicated atrial septal defect angiocardiography does not show the shunt as does cardiac catheterization. Angiocardiography does not measure the degree of pulmonary stenosis, and indeed may fail to show minor degrees of the condition; on the other hand, by successful cardiac catheterization pulmonary stenosis can not only be shown but its effects measured, and improvement after surgical treatment can be assessed.

In cases of congenital heart disease presenting no great difficulty in diagnosis, the findings of catheterization can be expected to support the diagnosis. In those instances when difficulties arise in clinical diagnosis, usually when multiple malformations exist, cardiac catheterization may be of great value. If the investigation fails to supply useful information, and this is still a frequent source of disappointment, the reason is either that the catheter cannot be introduced into all the compartments of the heart desirable, or because alternative explanations are possible for the abnormal intracardiac pressures or oxygen contents of the blood samples that have been found. In all but the simplest malformations it is necessary to bring every possible piece of evidence together before making a diagnosis.

\section{SUMmaRY}

Certain points in the technique of cardiac catheterization are discussed.

In congenital heart disease cardiac catheterization is not without danger. Six of 70 cases developed signs indicative of pulmonary or systemic thrombosis or embolism. One case died.

The difference in oxygen content of blood obtained from the venæ cavæ, right atrium, right ventricle, and pulmonary artery are discussed in relation to the diagnosis of septal defects and patent ductus arteriosus. In the absence of intracardiac shunts and patent ductus arteriosus the oxygen content of right atrial blood should not exceed;

(a) that of the superior vena cava by more than 2 volumes per cent * (Fig. 1);

(b) that of inferior vena caval blood by more than 3 volumes per cent (Fig. 2);

(c) that of the mean of superior and inferior vena caval blood by more than 2 volumes per cent (Fig. 3).

The oxygen content of right ventricular blood should not exceed that of right atrial blood by more than 1 volume per cent (Fig. 4). The oxygen content of pulmonary artery blood should not exceed that of right ventricular blood by more than 0.5 volumes per cent (Fig. 5).

The use of cardiac catheterization in the diagnosis of the following conditions is considered:

* In cases with normal hæmoglobin saturation a difference of oxygen content of 1 volume per cent amounts to 5 per cent difference in oxygen saturation. In polycythæmic cases the same difference of oxygen content represents a smaller difference in oxygen per cent saturation. 
Fallot's tetralogy, Eisenmenger's complex, transposition of the great vessels, pulmonary stenosis with closed ventricular septum, tricuspid and pulmonary atresia, truncus arteriosus, atrial and ventricular septal defects, Lutembacher's syndrome, patent ductus arteriosus, and pulmonary hæmangioma.

We are indebted to Dr. Maurice Cambell for his interest in these investigations, and for valuable discussions in the interpretation of clinical and catheterization findings. Our thanks are also due to the Departments of Medical Illustration and Photography for help with the illustrations.

\section{APPENDIX}

\section{Normal Standards for Cardiac Output}

Cournand (1945) gives the normal cardiac output for the healthy male adult when estimated by the catheter technique as $3 \cdot 1$ litres a minute per square metre of the body surface. The values for females and children are not known.

\section{Intracardiac Pressures}

Bloomfield, Cournand et at. (1946) give values for normal intracardiac pressures. Their pressure measurements are referred to the plane of $5 \mathrm{~cm}$. below the angle of Ludwig, and ours to the plane of the skin of the back. It is therefore necessary to add $10 \mathrm{~mm}$. $\mathrm{Hg}$ to their figures to make them comparable with ours. If this is done the figures for normal intracardiac pressures become:

\begin{tabular}{|c|c|c|c|}
\hline Right Atrium & & .. & 8 to $12 \mathrm{~mm} . \mathrm{Hg}$ \\
\hline $\begin{array}{l}\text { Right Ventricle } \\
\text { Systolic }\end{array}$ & & & 35 to $40 \mathrm{~mm}$. $\mathrm{F}$ \\
\hline Diastolic & . & & 5 to $15 \mathrm{~mm}$. \\
\hline Mean & & & $20 \mathrm{~mm} . \mathrm{H}$ \\
\hline Pulmonary Arte & & & \\
\hline Systolic & $\ldots$ & & 35 to $40 \mathrm{~mm}$. \\
\hline Diastolic & $\ldots$ & & 15 to $20 \mathrm{~mm}$. $\mathrm{I}$ \\
\hline Mean & $\ldots$ & & $25 \mathrm{~mm}$. \\
\hline
\end{tabular}

In our cases the systolic and diastolic pressures were obtained from Hamilton manometer records, and the mean pressure from the aneroid manometer readings.

\section{NOTES ON THE 18 CASES \\ - Fallot's Tetralogy*}

Case 1. The clinical diagnosis of Fallot's tetralogy was supported by the catheterization findings. The oxygen content of the right ventricular blood agreed with that from the right atrium, but the oxygen content of the pulmonary artery blood was distinctly lower. This finding was almost certainly an artefact due to obstruction of the stenosed pulmonary orifice by the catheter for several minutes before the specimen was obtained. Therefore, the oxygen content of the right ventricular blood had to be used in calculating the pulmonary blood flow.

Case 2. The clinical diagnosis of Fallot's tetralogy was supported by the catheterization findings. The increased oxygen content of the right atrial blood as compared with that from the venæ cavæ (see Fig. 1, 2, and 3) suggested the presence of an atrial septal defect, but this was made doubtful by the low oxygen content of the right ventricular blood (see p. 162). The mean of the values of the oxygen content of the vena caval samples was used in the calculation of the systemic blood flow.

Case 3. Clinically there was doubt whether the pulmonary shadows were due to collateral circulation or indicated Eisenmenger's complex. The findings, however, showed pulmonary stenosis to be present, and therefore support the diagnosis of Fallot's tetralogy. The significance of the lowered oxygen content of the pulmonary artery as compared with the right ventricular sample is uncertain. It is probably due to the catheter materially obstructing the lumen of the stenosed artery, though it may also have been due to the restlessness of the child. Because of this the oxygen content of the right ventricular sample was used in the calculation of the pulmonary blood flow. The pulmonary stenosis was of moderate severity and a venoarterial shunt occurred presumably through a ventricular septal defect.

Case 4. The clinical diagnosis was pulmonary stenosis with doubt about the condition of the ventricular septum. Samples were taken from the trunk and from the right and left branches of the pulmonary artery and all showed the same oxygen content which was considerably higher than that obtained on samples from

* All these four cases were greatly improved by subclavian-pulmonary anastemosis or rescetion of the infundibulum (Case 4). 
the right ventricle. This finding suggested that either a patent ductus arteriosus or a high ventricular septal defect was present. In the absence of a ductus murmur the latter explanation seemed the more likely one, and at subsequent operation no evidence of a patent ductus arteriosus was found. Evidence of mixing of the blood of the two ventricles in both directions through the ventricular septal defect was given, not only by the increased oxygen content of the pulmonary artery blood, but also by the decreased saturation of the arterial blood. Though the blood flow calculations suggested a slight preponderance of arteriovenous shunt through the defect, the figure for this was well within the limits of experimental error (Dexter et al., 1947). This case appeared to be one of pulmonary stenosis with a small high ventricular septal defect.

\section{Pulmonary Stenosis with Closed Ventricular Septum}

Case 5. The clinical diagnosis was pulmonary stenosis. Catheterization results showed that pulmonary stenosis was present but gave no evidence of a septal defect. The mild degree of pulmonary stenosis appeared to be largely compensated for by the increased systolic pressure of the right ventricle so that there was only a slight reduction of the pulmonary flow. The small calculated venoarterial intracardiac shunt was within the limits of experimental error, and in view of the normal arterial oxygen saturation such a shunt was unlikely.

Case 6. In this case of pulmonary stenosis with an intact ventricular septum the right ventricle was only once entered, and though the pressure in it was read no blood sample was obtained. This patient had signs of congestive failure which presumably account for the raised right atrial pressure and the enlargement of this chamber demonstrated by the catheter. The same oxygen saturation was found in samples taken from two different points in the right atrium. The right atrial sample was therefore considered to represent mixed venous blood and used for the calculation of the systemic flow. The low value of the latter, and the almost normal arterial oxygen saturation indicate that the pulmonary blood flow is much reduced and that not more than a minimal septal defect is present. Post-mortem, the pulmonary valves were severely stenosed and a very small opening to a probe was found through the valve covering the foramen ovale.

Case 7. The clinical diagnosis was of severe pulmonary stenosis, and at first angiocardiography failed to show any right to left shunt. The catheterization findings are incomplete because the patient did not stand the procedure well. The extremely low value for the oxygen saturation of the blood from the right pulmonary artery is almost certainly an artefact caused by the prolonged obstruction to the stenosed artery by the catheter, especially as a sample taken from the common pulmonary artery two minutes later showed a still lower oxygen saturation of only 15 per cent. There is no doubt that both pulmonary and systemic blood flows were very low, though accurate figures cannot be given. The lowered arterial oxygen saturation was evidence of a small venoarterial shunt. Post-mortem, severe pulmonary stenosis was found and a slit-like opening ( 7 by $3 \mathrm{~mm}$.) in the valve covering the foramen ovale.

Case 8. The catheterization findings supported the diagnosis of pulmonary stenosis and showed up a significant venoarterial shunt. The right atrial and right ventricular samples were in good agreement and when compared with them the lowered oxygen saturation of the pulmonary blood sample suggested that the catheter had obstructed the pulmonary artery. This was also suggested by the sense of release from grip which was felt when the catheter was withdrawn from the pulmonary artery. The right ventricular sample was used, therefore, in calculating the pulmonary blood flow. A pulmonary vein draining blood 97 per cent saturated with oxygen into the right atrium was demonstrated; the right atrial sample, therefore, has probably a higher oxygen content than that of true mixed venous blood. The mean oxygen content of the vena caval blood samples would have been more accurate in calculating the systemic blood flows, but unfortunately these had not been taken. The calculated systemic blood flow is therefore likely to be higher than the actual one. This appears to be a case of marked pulmonary stenosis with a moderate venoarterial shunt, and no evidence is obtained as to whether the shunt occurs through the atrial or ventricular septum.

\section{Eisenmenger's Syndrome}

Case 9. The clinical diagnosis of Eisenmenger's complex was supported by the catheterization results. There was clear evidence of interventricular mixture of blood, but no preponderance of shunt either to the right or left. The difference in oxygen saturation of the right ventricular and pulmonary artery blood samples suggests a high septal defect and some degree of left to right shunt. Pressure tracings from this case are shown in Fig. 7.

\section{Transposition of the Great Vessels}

Case 10. A reliable diagnosis could not be made before catheterization, though transposition with a septal defect was suspected. The finding that the pulmonary artery blood was 82 per cent saturated whilst that of the systemic artery was only 72 per cent made it clear that this was a case of transposition of the great vessels. The figure for the pulmonary artery blood oxygen saturation was duplicated in samples from both the common trunk and the right branch of the pulmonary artery, and the figure for the arterial oxygen saturation was confirmed $(68 \%)$ by a second arterial sample collected 5 hours after the catheterization. 
Findings in 18 Illustrative Cases

\begin{tabular}{|c|c|c|c|c|c|c|c|c|}
\hline \multirow[b]{2}{*}{$\begin{array}{l}\text { Case } \\
\text { No. }\end{array}$} & \multirow{2}{*}{$\begin{array}{l}\text { Reference } \\
\text { number, } \\
\text { initials }\end{array}$} & \multirow[b]{2}{*}{ Sex, age } & \multirow{2}{*}{$\begin{array}{l}\text { Surface } \\
\text { area, } \\
\text { sq. metres } \\
\text { (1) }\end{array}$} & \multirow{2}{*}{$\begin{array}{c}\mathrm{O}_{2} \\
\text { consumption } \\
\text { ml./min./ sq. } \\
\text { metre. } \\
\text { B.M.R. \% } \\
\text { of normal (2) }\end{array}$} & \multicolumn{4}{|c|}{ Pressures (mm. Hg.) from skin of back (3) } \\
\hline & & & & & $\begin{array}{l}\text { Right } \\
\text { atrium }\end{array}$ & $\begin{array}{c}\text { Right } \\
\text { ventricle }\end{array}$ & $\begin{array}{l}\text { Pulmonary } \\
\text { artery }\end{array}$ & $\begin{array}{l}\text { Systemic } \\
\text { artery }\end{array}$ \\
\hline & \multicolumn{2}{|c|}{ Fallot's Tetralogy } & & & & 69 & & $198 / 00$ \\
\hline 1. & $\begin{array}{l}\text { O105 } \\
\text { K. C. }\end{array}$ & $\begin{array}{l}F \\
15\end{array}$ & $1 \cdot 59$ & $\begin{array}{l}132 \\
+6 \%\end{array}$ & 10 & 62 & 10 & $128 / 90$ \\
\hline 3. & O051 & F & 0.82 & $\begin{array}{l}194^{\circ} \\
+20^{\circ}\end{array}$ & $4 /-2$ & $105 /-5$ & $15 / 0$ & $80 / 55$ \\
\hline 4. & $\begin{array}{l}\text { CB11 } \\
\text { A. A. }\end{array}$ & $\begin{array}{l}F \\
20\end{array}$ & $1 \cdot 70$ & $\begin{array}{l}115 \\
-6 \%\end{array}$ & 12 & 37 & 16 & $108 / 70$ \\
\hline & \multicolumn{4}{|c|}{ Pulmonary Stenosis with closed Ventricular Septum } & & & & \\
\hline 5. & $\begin{array}{l}\text { P206 } \\
\text { J. F. }\end{array}$ & $\begin{array}{l}M \\
16\end{array}$ & $1 \cdot 54$ & $\begin{array}{l}132 \\
-14 \%\end{array}$ & $10 / 0$ & $140 / 21$ & $40 / 21$ & $130 / 80$ \\
\hline 6. & $\begin{array}{l}\text { P031 } \\
\text { M. C. }\end{array}$ & $\begin{array}{c}F \\
22\end{array}$ & 1.53 & $\begin{array}{l}120 \\
-5 \%\end{array}$ & 24 & 70 & - & $115 / 85$ \\
\hline 7. & $\begin{array}{l}\text { H117 } \\
\text { D. S. }\end{array}$ & $\begin{array}{l}\mathrm{F} \\
30\end{array}$ & 1.53 & $\begin{array}{l}118 \\
-8 \%\end{array}$ & - & $100+$ & 16 & - \\
\hline 8. & $\begin{array}{l}\text { O207 } \\
\text { D. W. }\end{array}$ & $\begin{array}{l}\mathrm{F} \\
26\end{array}$ & $1 \cdot 48$ & $\begin{array}{r}137 \% \\
+10 \%\end{array}$ & 11 & 85 & 11 & $120 / 75$ \\
\hline 9. & Eisenmenger & S Complex & $1 \cdot 42$ & 152 & $\mathbf{0}$ & $95 /-5$ & $95 / 55$ & $130 / 80$ \\
\hline & O. D. & 23 & & $+20 \%$ & & & & \\
\hline 10. & $\begin{array}{c}\text { Transpositio } \\
0076\end{array}$ & $\underset{\mathbf{M}}{\text { of Great } V}$ & ssels ${ }_{1.09}$ & 169 & 10 & 47 & 88 & $100 / 70$ \\
\hline 10. & E. T. & 14 & & $+6 \%$ & & & & $100 / 10$ \\
\hline 11. & $\begin{array}{l}\text { OA06 } \\
\text { K. M. }\end{array}$ & $\begin{array}{r}\mathbf{M} \\
7\end{array}$ & 0.82 & $\begin{array}{l}182 \\
+3 \%\end{array}$ & 8 & $65 / 10$ & $80 / 50$ & $85 / ?$ \\
\hline & Truncus Art & riosus & & & & & & \\
\hline 12. & $\begin{array}{l}\text { P098 } \\
\text { H. W. }\end{array}$ & $\begin{array}{c}F \\
12\end{array}$ & 0.96 & $\begin{array}{c}230 \\
+54 \%\end{array}$ & $4 /-8$ & $117 / 7$ & - & $\begin{array}{c}120 / 78 \\
\text { Hamilton } \\
\text { manometer }\end{array}$ \\
\hline & Pulmonary & id/or Tricus & id Atresia & & & & & \\
\hline 13. & $\begin{array}{l}\text { O229 } \\
\text { C. L. }\end{array}$ & $\begin{array}{c}F \\
6\end{array}$ & 0.69 & $\begin{array}{c}222 \\
+30 \%\end{array}$ & 4 & - & - & $\begin{array}{c}160 / 20 \\
\begin{array}{c}\text { (left } \\
\text { tricle) }\end{array}\end{array}$ \\
\hline 14. & $\begin{array}{l}\text { O021 } \\
\text { V. F. }\end{array}$ & $\begin{array}{l}F \\
14\end{array}$ & $1 \cdot 12$ & $\begin{array}{c}178 \\
+25 \%\end{array}$ & 14 & - & 一 & $100 / 55$ \\
\hline 15. & $\begin{array}{l}\text { P057 } \\
\text { S. H. }\end{array}$ & $\begin{array}{l}\text { M } \\
19\end{array}$ & 1.32 & $\begin{array}{r}168 \\
+19 \%\end{array}$ & 11 & - & - & $95 / 60$ \\
\hline 16. & $\begin{array}{l}\text { Patent Duct } \\
\text { O280 } \\
\text { L. S. }\end{array}$ & $\begin{array}{l}\text { Arteriosus } \\
\text { M } \\
27\end{array}$ & $1 \cdot 70$ & $\begin{array}{r}138 \\
0\end{array}$ & 9 & 14 & 18 & $130 / 55$ \\
\hline 17. & $\begin{array}{l}\text { Atrial Septa } \\
\text { C227 } \\
\text { J. M. }\end{array}$ & $\begin{array}{c}\text { Defect } \\
\text { M } \\
25\end{array}$ & $\begin{array}{c}\text { mbacher's } S\} \\
1.53\end{array}$ & $\begin{array}{c}\text { ndrome) } \\
167 \\
+12 \%\end{array}$ & 20 & 62 & 72 & $105 / 75$ \\
\hline 18. & $\begin{array}{l}\text { Pulmonary } \\
\text { D. C. }\end{array}$ & $\begin{array}{c}\text { emangioma } \\
\mathbf{M} \\
27\end{array}$ & $1 \cdot 57$ & $\begin{array}{l}147 \\
+7 \%\end{array}$ & 8 & 17 & 15 & $105 / 80$ \\
\hline
\end{tabular}

(1) From Du Bois formula.

(2) Percentage of normal calculated on Boothby and Sandiford's (1929) figures. 


\begin{tabular}{|c|c|c|c|c|c|c|c|c|c|}
\hline \multicolumn{7}{|c|}{$\begin{array}{l}\text { Oxygen content (volumes \%) } \\
\text { Percentage saturation }\end{array}$} & \multicolumn{3}{|c|}{$\begin{array}{l}\text { Blood flow } \\
\text { litres/min./sq. metre }\end{array}$} \\
\hline $\begin{array}{l}\text { Inferior } \\
\text { vena } \\
\text { cava }\end{array}$ & $\begin{array}{l}\text { Superior } \\
\text { vena } \\
\text { cava }\end{array}$ & $\begin{array}{l}\text { Right } \\
\text { atrium }\end{array}$ & $\begin{array}{c}\text { Right } \\
\text { ventricle }\end{array}$ & $\begin{array}{l}\text { Pul- } \\
\text { monary } \\
\text { artery }\end{array}$ & Artery & $\begin{array}{l}\text { Total } \\
\text { capacity }\end{array}$ & $\begin{array}{l}\text { Pul- } \\
\text { monary }\end{array}$ & Systemic & $\underset{(4)}{\text { Shunt }}$ \\
\hline $\begin{array}{l}16 \cdot 9 \\
56 \% \\
20 \cdot 5 \\
60 \% \\
11 \cdot 3 \\
54 \% \\
- \\
-\end{array}$ & $\begin{array}{l}15 \cdot 7 \\
52 \% \\
18 \cdot 5 \\
54 \% \\
13 \cdot 5 \\
65 \% \\
14 \cdot 2 \\
60 \%\end{array}$ & $\begin{array}{l}16 \cdot 2 \\
54 \% \\
23.0 \\
68 \% \\
12 \cdot 2 \\
58 \% \\
13.9 \\
59 \%\end{array}$ & $\begin{array}{l}16 \cdot 2 \\
54 \% \\
20 \cdot 7 \\
61 \% \\
12 \cdot 4 \\
59 \% \\
14 \cdot 7 \\
62 \%\end{array}$ & $\begin{array}{l}14 \cdot 1 \\
47 \% \\
20 \cdot 5 \\
60 \% \\
11 \cdot 0 \\
53 \% \\
16.4 \\
69 \%\end{array}$ & $\begin{array}{l}18 \cdot 5 \\
62 \% \\
24 \cdot 5 \\
72 \% \\
16 \cdot 7 \\
80 \% \\
21 \cdot 1 \\
89 \%\end{array}$ & $\begin{array}{c}30 \cdot 2 \\
\overline{34 \cdot 1} \\
\overline{20 \cdot 9} \\
\overline{23 \cdot 8} \\
-\end{array}$ & $\begin{array}{l}1.0 \\
1.4 \\
2.6 \\
1.9\end{array}$ & $\begin{array}{l}6 \cdot 0 \\
3 \cdot 2 \\
4 \cdot 3 \\
1 \cdot 7\end{array}$ & $\begin{array}{r}5.0 \\
1.8 \\
1.7 \\
-0.2\end{array}$ \\
\hline $\begin{array}{l}12 \cdot 5 \\
78 \% \\
- \\
- \\
- \\
-\end{array}$ & $\begin{array}{c}10 \cdot 2 \\
63 \% \\
- \\
- \\
- \\
- \\
-\end{array}$ & $\begin{array}{c}10 \cdot 9 \\
68 \% \\
9 \cdot 0 \\
37 \% \\
- \\
\overline{12 \cdot 9} \\
45 \%\end{array}$ & $\begin{array}{c}10 \cdot 3 \\
64 \% \\
- \\
- \\
- \\
\overline{13 \cdot 5} \\
47 \%\end{array}$ & $\begin{array}{c}10 \cdot 3 \\
64 \% \\
- \\
\overline{-} \\
9 \cdot 8 \\
29 \% \\
6 \cdot 3 \\
22 \%\end{array}$ & $\begin{array}{l}15 \cdot 4 \\
96 \% \\
22 \cdot 0 \\
91 \% \\
26 \cdot 4 \\
77 \% \\
19 \cdot 8 \\
69 \%\end{array}$ & $\begin{array}{l}\frac{16 \cdot 1}{24 \cdot 3} \\
\frac{-}{34 \cdot 5} \\
\frac{-}{28 \cdot 6} \\
-\end{array}$ & $\begin{array}{c}2.6 \\
\text { Very } \\
\text { small } \\
\text { Very } \\
\text { small } \\
1 \cdot 0\end{array}$ & $\begin{array}{c}3.0 \\
0.85 \\
\text { Very } \\
\text { small } \\
2.0\end{array}$ & $\begin{array}{c}0.4 \\
\text { Very } \\
\text { small } \\
\text { Small } \\
1.0\end{array}$ \\
\hline $\begin{array}{l}18 \cdot 8 \\
54 \%\end{array}$ & $\begin{array}{l}22 \cdot 5 \\
64 \%\end{array}$ & $\begin{array}{l}19 \cdot 8 \\
57 \%\end{array}$ & $\begin{array}{l}21 \cdot 6 \\
62 \%\end{array}$ & $\begin{array}{l}25 \cdot 6 \\
74 \%\end{array}$ & $\begin{array}{l}26 \cdot 8 \\
77 \%\end{array}$ & $\frac{34 \cdot 7}{-}$ & $2 \cdot 1$ & $2 \cdot 2$ & - \\
\hline $\begin{array}{l}\overline{-} \\
\overline{15 \cdot 6} \\
65 \%\end{array}$ & $\begin{array}{l}15 \cdot 8 \\
61 \% \\
14 \cdot 5 \\
60 \%\end{array}$ & $\begin{array}{l}14 \cdot 0 \\
54 \% \\
15 \cdot 4 \\
64 \%\end{array}$ & $\begin{array}{l}19 \cdot 6 \\
75 \% \\
20 \cdot 2 \\
84 \%\end{array}$ & $\begin{array}{l}21 \cdot 5 \\
82 \% \\
20 \cdot 8 \\
86 \%\end{array}$ & $\begin{array}{l}18 \cdot 8 \\
72 \% \\
16 \cdot 9 \\
70 \%\end{array}$ & $\begin{array}{c}26 \cdot 1 \\
24 \cdot 2 \\
-\end{array}$ & $\begin{array}{l}5 \cdot 1 \\
8 \cdot 3\end{array}$ & $\begin{array}{r}3 \cdot 5 \\
12 \cdot 1\end{array}$ & $\begin{array}{r}-1.6 \\
3.8\end{array}$ \\
\hline - & - & $\begin{array}{l}13 \cdot 2 \\
61 \%\end{array}$ & $\begin{array}{l}14 \cdot 1 \\
65 \%\end{array}$ & - & $\begin{array}{l}13 \cdot 1 \\
60 \%\end{array}$ & $\underline{21 \cdot 8}$ & $\begin{array}{l}\text { Not } \\
\text { reduced }\end{array}$ & - & - \\
\hline $\begin{array}{r}7 \cdot 8 \\
25 \%\end{array}$ & $\begin{array}{l}10 \cdot 8 ? \\
34 \% ?\end{array}$ & $\begin{array}{r}6 \cdot 4 \\
20 \%\end{array}$ & $\begin{array}{l}6 \\
2 \%\end{array}$ & $\begin{array}{c}\text { (Left } \\
\text { atrium) } \\
9 \cdot 6 \\
30 \%\end{array}$ & $\begin{array}{c}\text { (Left ven- } \\
\text { tricle) } \\
11 \cdot 4 \\
36 \%\end{array}$ & $31 \cdot 4$ & - & - & - \\
\hline $\begin{array}{l}19 \cdot 6 \\
62 \% \\
17 \cdot 4 \\
59 \%\end{array}$ & $\begin{array}{l}- \\
\overline{19 \cdot 2} \\
65 \%\end{array}$ & $\begin{array}{l}18 \cdot 6 \\
59 \% \\
16 \cdot 5 \\
56 \%\end{array}$ & $\begin{array}{l}- \\
-\end{array}$ & $\begin{array}{l}- \\
-\end{array}$ & $\begin{array}{l}25 \cdot 6 \\
81 \% \\
21 \cdot 7 \\
73 \%\end{array}$ & $\begin{array}{c}31 \cdot 6 \\
29 \cdot 8 \\
-\end{array}$ & $\begin{array}{c}4.4 \\
>1 \cdot 4<3.5\end{array}$ & $\begin{array}{c}\text { app. } 2 \cdot 5 \\
3 \cdot 2\end{array}$ & $\begin{array}{l}-1.9 \\
\text { veno- } \\
\text { arterial }\end{array}$ \\
\hline - & - & $\begin{array}{l}12 \cdot 9 \\
64 \%\end{array}$ & $\begin{array}{l}14 \cdot 0 \\
70 \%\end{array}$ & $\begin{array}{l}15 \cdot 5 \\
77 \%\end{array}$ & $\begin{array}{l}18 \cdot 5 \\
92 \%\end{array}$ & $\underline{20 \cdot 2}$ & $3 \cdot 7$ & $2 \cdot 4$ & $-1 \cdot 3$ \\
\hline - & $\begin{array}{l}12 \cdot 1 \\
52 \%\end{array}$ & $\begin{array}{l}12 \cdot 2 / 15 \cdot 7 \\
52 \% / 67 \%\end{array}$ & $\begin{array}{l}15 \cdot 6 / 17 \cdot 3 \\
67 \% / 74 \%\end{array}$ & $\begin{array}{l}16 \cdot 2 \\
69 \%\end{array}$ & $\begin{array}{l}21 \cdot 5 \\
92 \%\end{array}$ & $\begin{array}{c}23 \cdot 5 \\
-\end{array}$ & $2 \cdot 7$ & $1 \cdot 8$ & -0.9 \\
\hline $\begin{array}{l}23.6 \\
75 \%\end{array}$ & $\begin{array}{l}21 \cdot 1 \\
66 \%\end{array}$ & $\begin{array}{l}21 \cdot 0 \\
66 \%\end{array}$ & $\begin{array}{l}20 \cdot 6 \\
65 \%\end{array}$ & $\begin{array}{l}21 \cdot 2 \\
67 \%\end{array}$ & $\begin{array}{l}23 \cdot 1 \\
73 \%\end{array}$ & $\frac{31 \cdot 6}{-}$ & $\begin{array}{c}1 \cdot 7 \\
\text { (alveoli) }\end{array}$ & $7 \cdot 0$ & $\begin{array}{c}5 \cdot 3 \\
\text { (hæman- } \\
\text { gioma) }\end{array}$ \\
\hline
\end{tabular}

(3) A single number indicates mean pressure (aneroid manometer); two numbers indicate systolic and diastolic pressure.

(4) A negative sign indicates an arteriovenous shunt, otherwise the shunts are venoarterial. 
This transposition may have been more functional than anatomical because though the catheter could be passed easily through into the pulmonary artery it could not be passed into the aorta. Mean blood pressures only were obtained, but it was likely that systolic pressures in the right ventricle, pulmonary artery, and aorta were equal. Further evidence of considerable interventricular mixing of blood was given by the higher oxygen content of the right ventricle as compared with the superior vena cava and right atrial samples. The pulmonary blood flow was greatly increased. It was concluded that a large ventricular septal defect with transpositions of the great vessels was present.

Case 11. The clinical diagnosis lay between transposition with a septal defect and Eisenmenger's complex. The catheterization was done under avertin and pentothal anæsthesia. The results showed interventricular mixing of blood by the increase in oxygen content in passing from the right atrium to ventricle, and demonstrated the transposition by the fact that the oxygen saturation of the arterial blood was markedly lower than that obtained from the pulmonary artery. For some reason unknown the systolic pressure in the pulmonary artery appeared to be higher than that in the right ventricle. The calculated blood flows were greatly increased. The final diagnosis was of transposition of the great vessels with a ventricular septal defect.

\section{Truncus Arteriosus}

Case 12. The clinical diagnosis of a truncus arteriosus was supported by the results of catheterization. A pulmonary vein draining blood ( $97 \%$ saturated) into the right atrium was demonstrated, and also an atrial septal defect. The catheter passed into what appeared to be a vessel of wide diameter (? truncus) and on into a right-sided aortic arch. No pulmonary branches were demonstrated. The blood samples were of limited value because the child was anxious and cried at times, but they indicated that complete mixing of systemic and pulmonary venous bloods had occurred in the common atrium. The systemic blood flow cannot be computed because no sample of mixed venous blood was obtainable as the child finally ceased to co-operate before vena caval samples could be obtained. Assuming that the pulmonary vessels are derived from a truncus arteriosus, the pulmonary blood flow can be calculated as 3 litres a minute per square metre of body surface. The conclusions to be drawn from the investigation are that an atrial septal defect was present, and that an anomalous pulmonary vein drained into the right atrium; there was evidence in favour of a common arterial trunk and the presence of two ventricles, but the existence of a pulmonary artery cannot be ruled out.

\section{Tricuspid Atresia and Pulmonary Atresia}

Case 13. The clinical diagnosis in this case was tricuspid atresia. The child was catheterized under only local anæsthesia and remained co-operative throughout. From the right atrium the catheter entered what was at first thought to be a small right ventricle, as judged by the position of the catheter and the pressure measured. The sample of blood obtained from it, however, was only 2 per cent saturated and it seems more likely that the structure entered was the coronary sinus, which the catheter had obstructed. The catheter was withdrawn and the left atrium entered through a large atrial septal defect; from there the tip was advanced into the left ventricle (Fig. 11). For fear of injuring the endocardium the catheter was not further manipulated in the ventricle and the aorta was not entered. As all blood samples, especially the one obtained from the right ventricle, were of such low oxygen content calculation of blood flows does not appear to be justified. The conclusions drawn were that the child had an atrial septal defect through which a venoarterial shunt occurred. The pressure tracings are shown in Fig. 12.

At the end of the catheterization the child complained of nausea and vomited twice, following which she passed into coma. Respirations stopped about two minutes later when a feeble pulse could still be felt. She improved with artificial respiration and oxygen and regained consciousness about 10 minutes later. One month later she had an angiocardiogram, and a few weeks later she suddenly collapsed in bed and died. The post-mortem findings were a large atrial septal defect producing what was practically a common atrium, a small right ventricle with hypertrophied walls, narrowed tricuspid valve, and shortened chordæ tendineæ. There was a slit-like opening high in the ventricular septum and several small ones in the lower part of the septum. The aorta arose entirely from the right ventricle, from which also arose a hypoplastic pulmonary artery with under-developed but well separated cusps. A high degree of pulmonary subvalvular stenosis was present, narrowing the lumen to a little over $1 \mathrm{~mm}$. in diameter. The blood supply to the lungs arose from well developed anterior and superior bronchial arteries. This case was therefore strictly neither an example of tricuspid or of pulmonary atresia, but of complete transposition of the aorta and marked pulmonary stenosis. The case is being reported fully in the Guy's Hospital Reports.

C'ase 14. This girl was diagnosed clinically as a case of Fallot's tetralogy with a large compensating ductus arteriosus. She was twice catheterized but on neither occasion could an exit be found from the right atrium. Post-mortem, there was a large patent foramen ovale and atresia of the pulmonary orifice and a small right ventricle. There was a well developed pulmonary artery which was supplied from the aorta via a large patent ductus arteriosus. With the knowledge of the post-mortem findings the blood flows shown in the table were calculated. 
Case 15. The clinical diagnosis was tricuspid atresia. At catheterization no exit could be found from the right atrium into either the right ventricle or the left atrium. In the absence of a sure anatomical diagnosis two figures were calculated for the pulmonary blood flow, the larger assuming that the pulmonary blood supply was derived entirely from the arterial blood, and the smaller assuming that the pulmonary blood supply was derived from such mixed venous blood as was sampled in the right atrium. In either case it appears that the pulmonary blood flow was reduced.

\section{Patent Ductus Arteriosus}

Case 16. The obvious clinical diagnosis of patent ductus arteriosus was confirmed by the finding that there was a significantly higher oxygen content of the blood in both branches of the pulmonary artery than that in the right ventricle. It will be noticed that the oxygen content of the right ventricular blood is somewhat higher than that of the right atrial blood. This may be due to the right atrial sample not being a representative one, it may be questionable evidence of a ventricular septal defect, or perhaps evidence of regurgitation through the pulmonary valves; had vena caval samples been taken the answer to the first of these possibilities would have been available.

\section{Atrial Septal Defect and Mitral Stenosis (Lutembacher's Syndrome)}

Case 17. The catheterization findings confirmed the clinical diagnosis of atrial septal defect. The right atrial pressure was raised, as was also the mean right ventricular and pulmonary artery pressures. The samples of blood of various oxygen content obtained from the right atrium and ventricle gave evidence of incomplete mixing of blood therein. The slightly lowered oxygen saturation of the arterial blood suggests that there may be some admixture of venous blood from the right to the left atrium even though the overall shunt is arteriovenous. The systemic blood flow is significantly reduced and the pulmonary blood flow is a low normal value. These findings suggest that mitral stenosis is also present, making this case an example of Lutembacher's syndrome.

\section{Pulmonary Hamangioma}

Case 18. This case was diagnosed clinically. It was thought that catheterization had diagnosed an angioma of the liver, for it was found that the oxygen content of the inferior vena caval blood was the same as that of the arterial blood. In cases of cyanotic heart disease, however, it is not very unusual to find that the oxygen content of inferior vena caval blood is nearly that of the arterial blood, but it is unusual to find them the same. Since he was known to have arteriovenous fistulæ in lips and buttocks it was thought that the inferior vena caval specimen derived from the effluent of an angioma of the liver. The cardiac output was greatly increased and it can be calculated that about 75 per cent of the right ventricular output passed through the angioma rather than through the alveolar capillaries. The diagnosis was confirmed post mortem, but the diagnosis of the hepatic angioma proved to be incorrect, though dilated sinuses suggested that a large proportion of the increased systemic circulation was passing through the liver. This case is fully described by Baker and Trounce (1949).

\section{REFERENCES}

Allanby, K. D., and Campbell, M. (1949). Guy's Hosp. Rep., 98, 18.

Baker, C., Brock, R. C., Campbell, M., and Suzman, S. (1949). Brit. Heart J., 11, 170.

-, Brinton, W. D., and Channell, J. (1950). Guy's Hosp. Rep. (In the press.)

, and Trounce, J. R. (1949). Brit. Heart. J., 11, 109.

Baldwin, E. de F., Moore, L. V., and Noble, R. P. (1946). Amer. Heart J., 32, 152.

Bedford, D. E., Papp, C., and Parkinson, J. (1941). Brit. Heart J., 3, 37.

Bing, R. J., Hammond, M. M., Handelsman, J. C., Powers, S. R., Spencer, F. C., Eckenhoff, J. E., Goodale, W. T., Hafkenschiel, J. H., and Kety, S. S. (1949). Amer. Heart J., 38, 1.

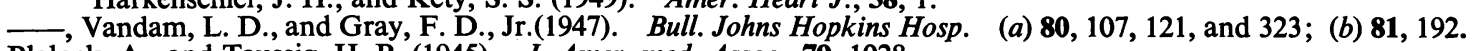
Blalock, A., and Taussig, H. B. (1945). J. Amer. med. Assoc., 79, 1028.

Bloomfield, R., Lawson, H., Cournand, A., Breed, E., and Richards, D., Jr. (1946). J. clin. Invest., $25,639$.

Boothby, W. M., and Sandiford, I. (1929). Proc. 13th Internat. Physiol. Congress, p. 32.

Brannon, E. S., Weens, H. S., and Warren, J. V. (1945). Amer. J. med. Sci., 210, 480.

Brock, R. C. (1948). Brit. med. J., 1, 1121.

Brody, H. (1942). Arch. Path., 33, 221.

Burchell, H. B., Parker, R. L., Dry, T. J., Wood, E. H., Pender, J. W., and Pugh, D. G. (1948). Proc. Staff Mayo Clinic, 23, 481 .

- Taylor, B. E., Pollack, A. A., Du Shane, J. W., and Wood, E. H. (1948). Ibid., $23,507$.

Campbell, M. (1948). Guy's Hosp. Rep., 97, 1.

C, and Hills, T. H. (1950). Brit. Heart J., 12, 65.

Cournand, A. (1945). Fed. Proc., 4, 207.

, Baldwin, J. S., Himmelstein, A. (1949). Cardiac Catheterization in Congenital Heart Disease, New York: Commonwealth Fund, p. 108. 
Cournand, A., Motley, H. L., Himmelstein, A., Dresdale, D., and Baldwin, J. (1947). Amer. J. Physiol., $150,267$. Dexter, L. (1947). Radiology, 48, 451.

—, Haynes, F. W., Burwell, C. S., Eppinger, E. C., Seibel, R. E., and Evans, J. M. (1947). J. clin. Invest., $26,547$.

,,,---- , Sagerson, R. P., and Evans, J. M. (1947). Ibid., 26, 554.

,,--- , Sosman, M. C., and Evans, J. M. (1947). Ibid., 26, 561.

Douglas, C. G., and Priestley, J. G. (1948). Human Physiology, Oxford: Clarendon Press.

Geiger, A. J., Anderson, H. C., Winkler, A. W., and Kaplan, H. S. (1946). Conn. State med. J., $10,895$.

Geraci, J. E., Dry. T. J., Burchell, H. B. (1948). . Proc. Staff Mayo Clinic, 23, 510.

Goodale, W. T., Lubin, M., Eckenhoff, J. E., Hafkenschiel, J. H., Curlacher, S. H., Landing, B. H., and Banfield, W. G. (1947). Proc. Exper. Biol. and Med., 66, 571.

Groom, D., Wood, E. H., Burchell, H. B., and Parker, R. L. (1948). Proc. Staff Mayo Clinic, $23,601$.

Hamilton, E. (1934). Amer. J. Physiol., 107, 427.

Handelsman, J. C., Bing, R. J., Campbell, J. A., and Griswold, H. E. (1948). Bull. Johns Hopkins Hosp., 82, 615.

Hickham, J. B., Cargill, W. H., and Golden, A. (1948). J. clin. Invest., 27, 290.

Hills, T. H. (1948). Brit. J. Radiol., 21, 511.

- and Stanford, R. W. (1950). Brit. Heart J., 12, 45.

Howarth, S., McMichael, J., and Sharpey-Schafer, E. P. (1947). Brit. Heart J., 9, 292.

Johnson, A. L., Wollin, D. G., and Ross, J. B. (1947). Canad. med. Assoc. J., 56, 549.

Kinney, T. D., Haynes, F. W., and Dexter, L. (1945). J. Lab. Clin. Med., 30, 1013.

Lutembacher, R. (1916). Arch. Mal. Cour, 9, 237.

Perry, E. L., Burchell, H. B., and Edwards, J. E. (1949). Proc. Staff Mayo Clinic, 24, 198.

Pollack, A. A., Taylor, B. E., Odel, H. M., and Burchell, H. B. (1948). Ibid., 23, 516.

Potts, W. J., and Gibson, S. (1948). J. Amer. med. Assoc., 127, 343.

Soulie, P., Servelle, M., and Schweisguth, O. (1949). Arch. Mal. Cour, 42, 1.

Taussig, H. B. (1947). Congenital Malformations of the Heart, New York: Commonwealth Fund, p. 618. (1948). Amer. Heart J., 36, 321

Taylor, B. E., Geraci, J. E., Pollack, A. A., Burchell, H. B., and Wood, E. H. (1948). Proc. Staff Mayo Clinic, $23,500$.

Warren, J. V., Stead, E. A., Jr., and Brannon, E. S. (1946). Amer. J. Physiol., 145, 458.

Wassermann, L. R., Dobson, R. L., and Lawrence, J. H. (1949). J. clin. Invest., 28, 60.

Wood, E. H., Geraci, J. E., and Groom, D. L. (1948). Fed. Proc., 7, 137. 